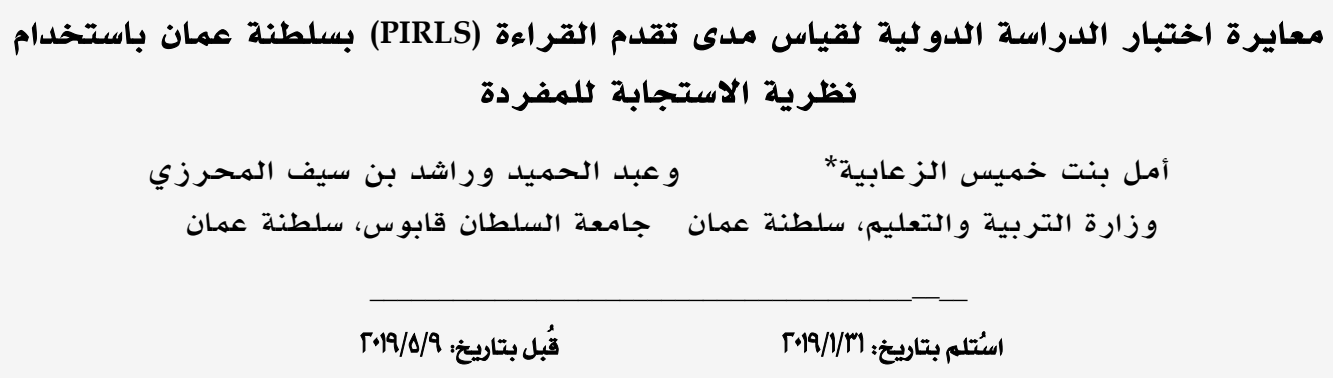

\title{
Calibrating PIRLS Test in Sultanate of Oman Using Item Response Theory
}

Amal k. Al-zaabi,*

The Ministry Of Education, Sultanate of Oman
Abdulhameed Hassan \& Rashid S. Al-mehrzi Sultan Qaboos University, Sultanate of Oman

Abstract: The study aimed to calibrate Oman data of the PIRLS test using the graded response model and to examine the psychometric properties of it, as well as identify the fit and unfit of its items. PIRLS2011 test booklets were used, which consisted of 146 test items (74 dichotomous and 72 polytomous). Items were divided into 13 booklets; each with two blocks (one literary and one informational). PIRLS test booklets were administered to 13 groups of fourth grade students in Sultanate of Oman with a total sample of 10394 students. Assumptions of IRT (unidimensionality and local independence) were examined and supported. Also, item fit was examined and supported using Samejima's graded response model. The data was analyzed by Multilog7.03 program to estimate both item and ability parameters. Results indicated that the assumptions of IRT were proved. Also, IRT analysis revealed that 8 items showed unfit which represents only $5 \%$ of the test items. So, this result confirms that the test has good psychometric properties under the IRT.

Keywords: PIRLS test, psychometric properties, fourth grade, Oman.

$\star$ amal.zaabe@moe.om 
و الحضـارية لهمثلي الحكومات، دـذلك فـإن

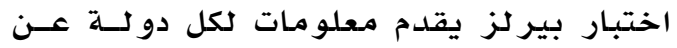

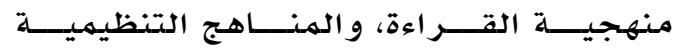

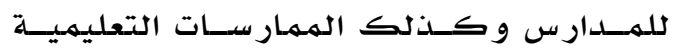
(Mullis, et. al, 2012)

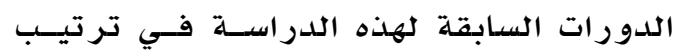

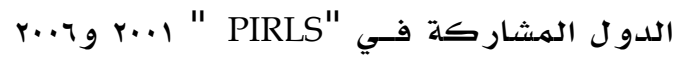

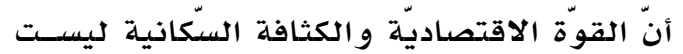

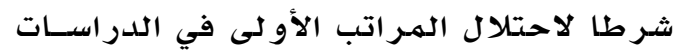

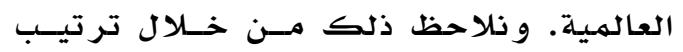

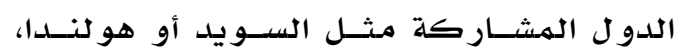
و هي دول صغيرة في حجمها و تعداد سـكانها،

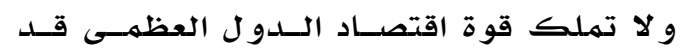

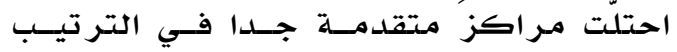

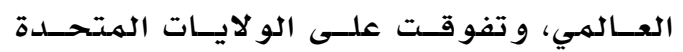

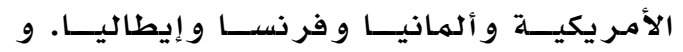
يدفعنا هذا إلى الإعتقاد بأن باستطاعة سلطنة

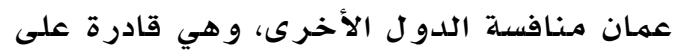
تحقيق نتائج جيدة يمكن أن تتحسن وتتطور

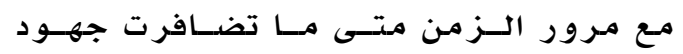

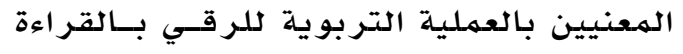
بشكل خاص و التعليهم بشـكل عـام . كـذلك

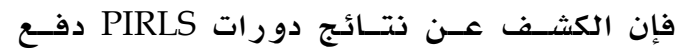
المسؤو لين في مجال التربية وقطاع التعليهم

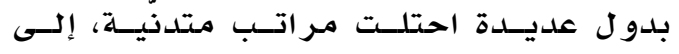

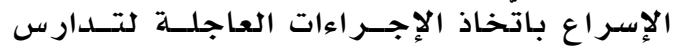

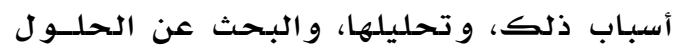

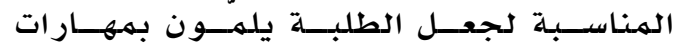
القر اءة و الكتابة. و بما أن اختبار ات الدرراسـات

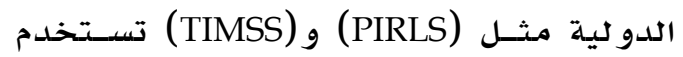

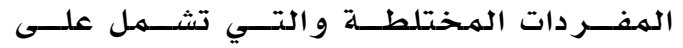

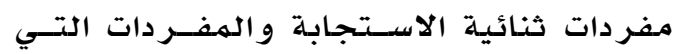
تحتاج إلى إجابة إنشائية من الطاسبـ. فإنـهـ

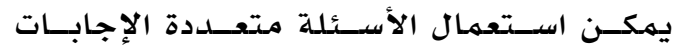
لتقييم أي واحدة من عمليـات الفهـهم، وبهـا

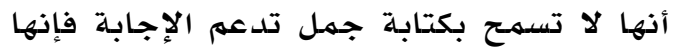

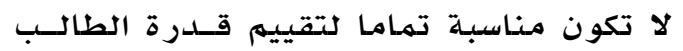
على تقديم شروح أو تقدير ات مفصـلـة. أمسا

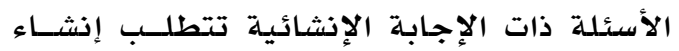

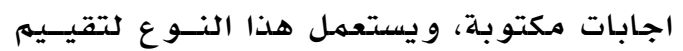

حر صت وزارة التربية و التعليهم فـي سـلطنة عمان علــى امـتلالك مؤشــر ات تســاعدها فــي

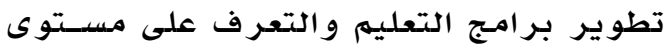

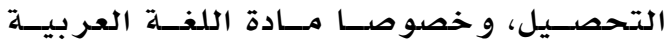

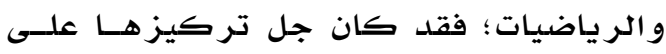

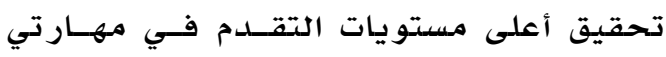

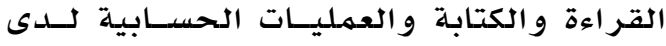
طلبة الحلقة الأو لى؛ لذلك شرعت في بنـاء اختبار ات تحصيلية ذات جودة عالية من خلالها الاستعانة بخبر اء مـختصين في هــذا المجـــال،

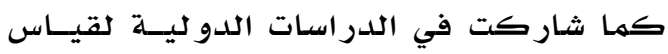
و تقو يهم مستو يات التحصيل الدر اسي مـع باقي دول العالم، بهــدف الوقـوف علـى مســتويات التحصــيل و مححاو لــة تطوير هـولــا و تحســـينها

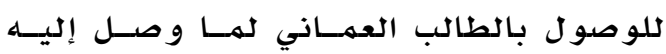
أقر انه من الدو ل الأخرى.

و من الدراسـات الدولية التسي شـاركت فيهـا الســلطنـة، هــي الدر اســـة الدو ليسـة (PIRLS) لقياس مدىى التقدم في القــراءة لــدى طلبـــة

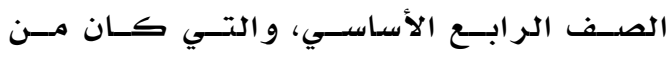

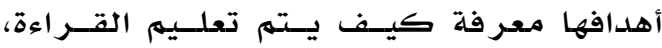

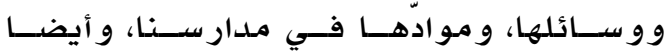

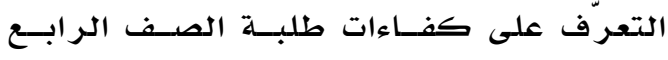
و إنجازاتهم في تحقيق الأهـداف الهـرســومـة

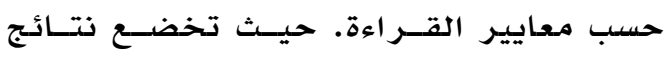
هذه الدراسـات للتحليل النوعي و الكمـي مــن

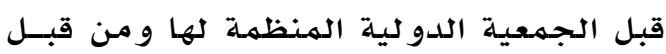
اللدول الهشاركة فيها، ويصدر بشأنها تقرير يحتوي على التفاصيل الخاصدة بكل دورة من (Mullis, Martin, Minnich, Drucker, دور اتها لدويا \& Ragan, 2012)

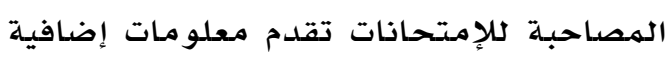

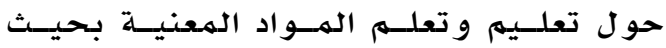
يستفيد منها المهختصون بالمنــاهج والتقيـيهم

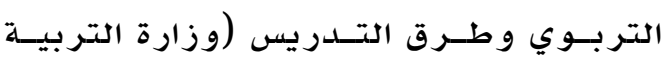

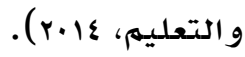

من الههم جدا معرفة أن الدول التي خضـغت لاختبار PIRLS2011 مختلفة جدا في في كثيـر اندا من الأسـاسيات منها أنظمة التعليهم التي تعكس

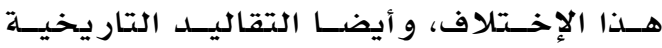


إلى الإجابة الصحيحة عـن طريـق التخهـين

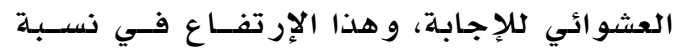
التخمين لبعض مفردات الإختبار يـؤدي إلـى وإِى

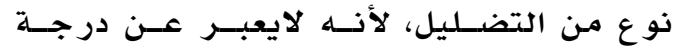

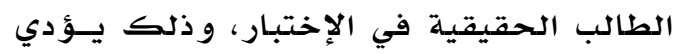

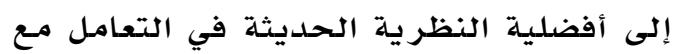

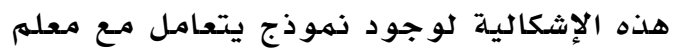

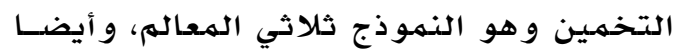
و جود نماذج الإستجابة الهتدرجهة التي تـؤدي

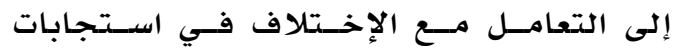

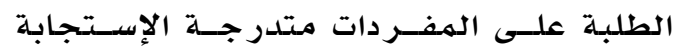

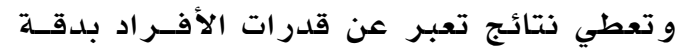

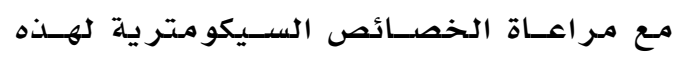

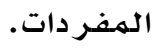

و في ظل مزايا نظرية الإسـتجابة للهفــردة

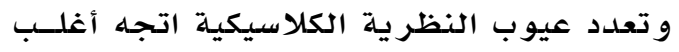
البـاحثين إلـى اسـتخدام مبـادئ نظريـة الإستجابة للمفردة في بناء اختبار ات جديدة أو التأكد من مطابقة مقاييس معدة مسـبـًا

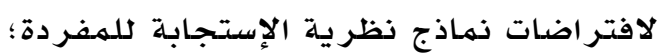
وذلك مسن أجسل تحقيـق شـرووط القيـاس الموضوضوعي للسمة أو القدرة المـر اد قيساسـها، تلك الشروط المتمثلة في استقلال تقـدير

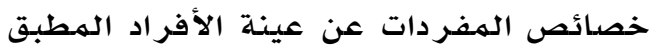

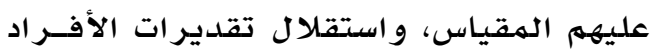

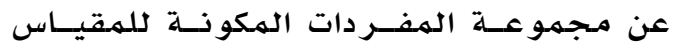

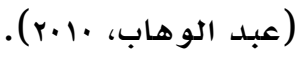

و مما يؤكد اتجاه الباحثين نحو استخدام

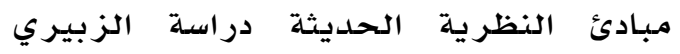

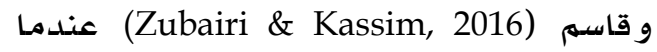

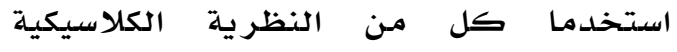
و نموذج راش وهو أحد نماذج الإستجابة للمفردة في تقييم كفاءة مفردات اختبار مكون من هب مفردة لقياس القراءة في اللغـة

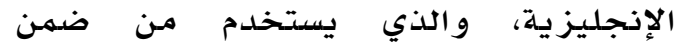
إجراءات قبول الطلبة في الجامعة الدور لية

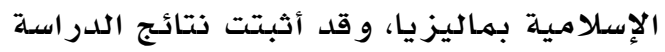
أنه لا يمكن الإكتفاء بالنظرية الكهلاسيكية

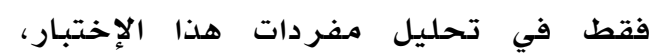

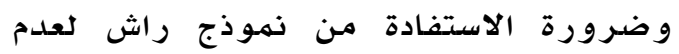

أي عملية من العمليات الأربع التركيز علـى الهـ

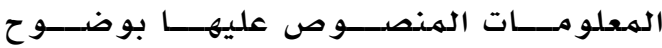

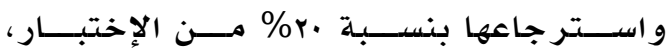

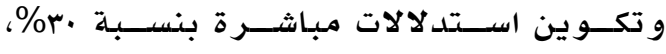

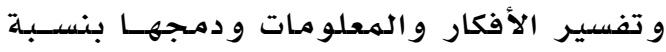

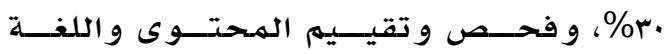

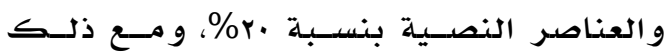
فهي أكثر ملائمهة لتقييهم جوانب من الفهـهم الذي يستدعي الطلبـة تقديهم دعـهم لإجـابـاتهم

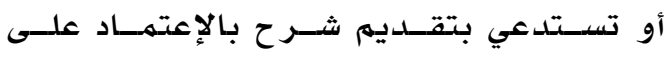

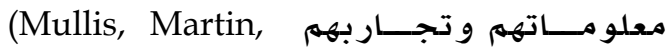
.Kennedy, Tong \& Sainsbury, 2009) و نظرًا لتوجه البـاحثين فـي مـجـال القيـاس

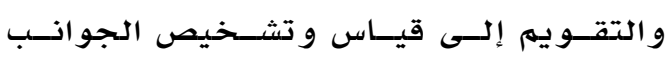
الهعرفية على أسـاس علهي دقيـق لإِســفـادة

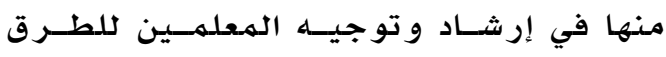

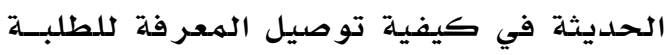

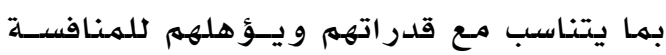

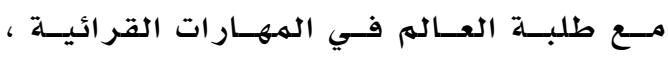

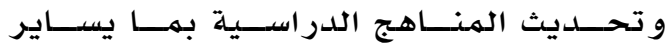

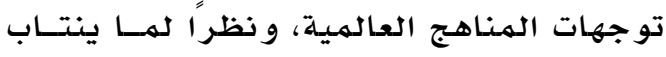

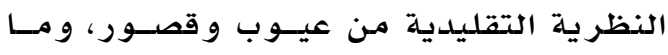

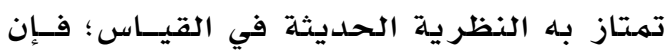

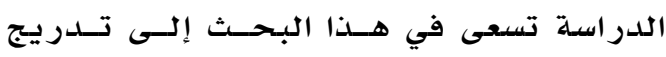
مفردات كتيبـات اختبــار الدراســة الدو ليــة

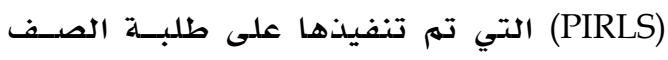

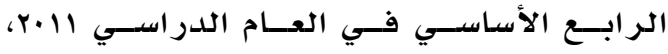
و ذلك لإمدادهم بنهموذج من هذه الاختبــار ات

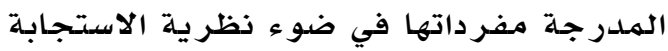

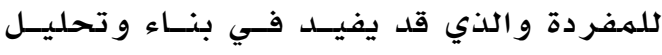

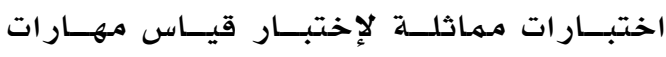

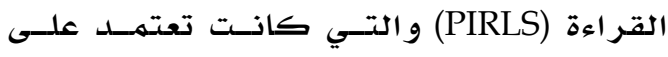

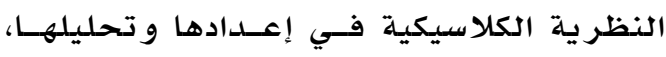

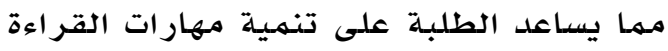

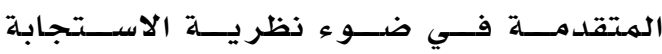
للمفر دة.

و ليس إعــاد الإختبــارات المشــابهة لنـــاذج هو السبب فقط وراء الدراسـة للقيام (PIRLS) بتدريج مفردات نماذج منها، و لكن هناك سبب لا يقل عن سابقه وهو ارتفاع نسبة الوصـول 


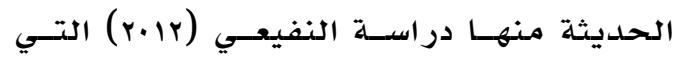
هدفت إلـى ايججـاد الخصصـائص السـيكومترية لاختبـار المصفوفات المتتابعة المتقدم، و الذي تم تطبيقه على عينهة بلغت (^•ی) من طلبـة الهـر حلتيـن الهـتوسطة و الثانوية، وتم إجـر اء مقار ذة بين النهــاذج اللو غاريتهيـة لتحديـد أيها أكثر مـلاءمهة لبيانات اختبار المصفوفات

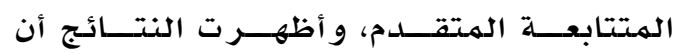
النهموذج ثنائي المعالم هـو الأكثـر مـلاءمــة لبيانات هذا الاختبار • ودراسـة أحهد (.l.r) ) التي هدفت إلى اعداد بطارية لتياس الإستعداد الأكاديهمي، حيث تم استخدام نموذج راش في بناء وتدريج بنـك الـك مفردات لقياس الإستعداد الأكاديهي. وتكون المقياس في صورته النهائيـة من TVY مفــردة مـن ذوع الاختيار مـن متعدد، و أظهرت نتـاءٔج الدراسلة أن بيانات المقيـاس اتسقت إلـى حــ كبيــر وحققـت درجــة عاليــة مسن حسـن المطابقة لأسس القياس الموضو ضي.

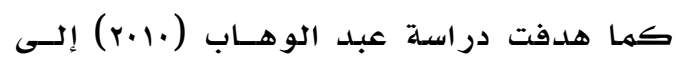
التحقق مـن افتر اضـات النظرية الححلـيثـة فـي بيانـات ثلاثــة اختبــارات (اختبــار التفكيـر الإسـتدلالي واختبـار التفكير النـاقـــ واختبـار

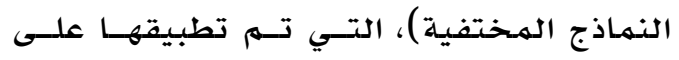
طلبـة مـر حلتي البكالوريوس و الليسـانس بكلية التربية بجامعة الهـنيا. تم استخدام النهـوذج ثلاثي المعالم فـي تـلدريج اختبـار التفكيـر الناقد واختبار النهـاذج الهختفيـة، بينهــا تـم استتخدام النهموذج ثنـائي الهعـالهم فـي تـدريـج مفردات اختبـار التفكير الإستدلالي، و أظهرت ذتـائج اللدراســة تحقـق افتر اضــات النظر يــة الححديثــة فــي بياذـات الإختبــارات الثلاثـــة، ووكـذلك تـهم تحديـد المفـردات المهلاءمــة لافتر اضدات النماذج المستخدمة في التـدريدج و حذف الهفردات غير الهمائهـة.

ويتبـين مـن عرض الدراسـات السـابقة التفـوق الذي أحرزته النظرية الححديثة فـي القيـاس، حيث أظهرت نتأُجها دقة وموضو عيـة نمـاذج السمات الكامنـة في إعداد الإختبارات وقيـاس
تقديهم النظرية الكلاسيكية لهعلومات ضرورية عن أداء الطلبة ذوي المستويات الهـختلفة في القدرة على كل مفردة في

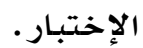

و كذلك دراسـة شيربوم ووكسوهن و كيــرن التـي (Scherbaum, Cohen \& Kern, 2006)

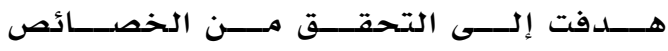
السيكومترية لمقياس الكفـاءة الذاتيـة العـام الذي بناه Sherer et al. (1982) بالهقارنة مـع مقياسين آخرين وهي مقيـاس الكفاءة الذاتية Schwarzer and العام الهحسوس الـذي بنـاه و مقيــاس الكفـاءة الذاتيـة Jerusalem (1995) Chen et al. العام الجديـد الـذي بنـاه (2001) و ذلك باستخدام نظرية الإستجابة نلهفـردة، و أوضحت النتائج إلى أن المقـاييس الثلاثـة متشـابهة فـي قيــاس الســمـة الكامنــة. و علـى الرغم مـن وجود اختتلافات بسـيطة بينهـا الا أن مقيــاس Chen et al. (2001) تفـوق عليهـا في معالم تهييز المفردات، وداتـة معلومــات الإختبار، مهمـا يشـير إلـى تمتحع الهقـاييس

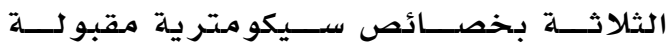
وقدرتها على التهـيـيـز بـين الأفـراد وقـدرة

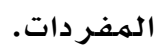

أمـا در اسـة أو يشي (Oishi , 2005) فقد هـدفت إلى التتحقـق مــن الخحصـائص الســيكومترية Satisfaction with لهقياس الر ضنا عن الحياة بــين مسجهـــ Life Scale (SWLS)

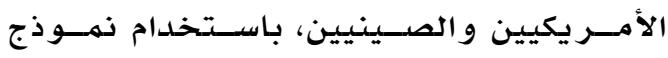
الهعادلة البنـائية ونهوذج ثنائي الهعالم التابع لنظرية الإستتجابة كلمفردة، أظهر ت النتـائج أن اسـتخحام نمسـوذج ثنـائي المعسالم أعطسى معلومهــات عاليـــة و نتــائج مـو ضـــو عيـة فــي الاختالاف بين المتوسطات للعينـيتين وأن هذا الإختلاف قد لا يرجع إلى تحيزات الهـردات، مها يشير إلى تفوق النظريسـة الحديثـــة فـي

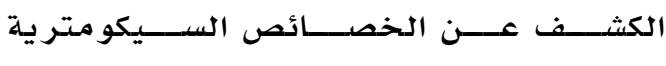
للهقياس. وهناك العلديد مـن الدر اسـات العربـيسة التـي توجهت إلى الاسـتفادة مــن مـزايـا النظريــة 
(Greaney, Prochnow \& Arrow, 2013 معرفة أسباب تدني مستوى طلبة نيوزيلانـدا

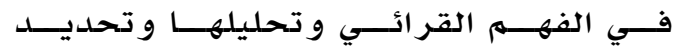

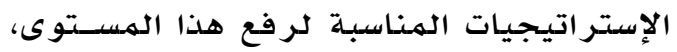

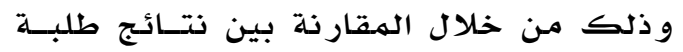

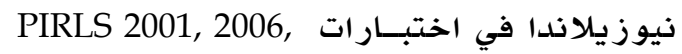

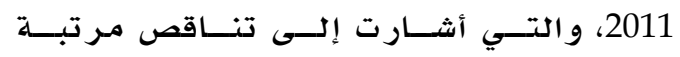

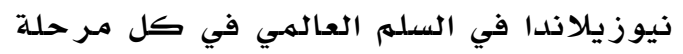

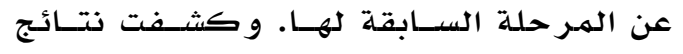

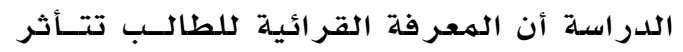

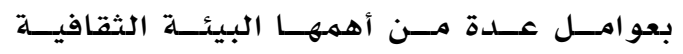
والاقتصدادية، لذلك أوصت بضرورة الهول استبدال

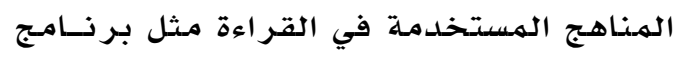

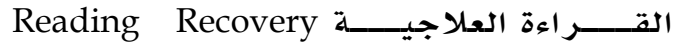

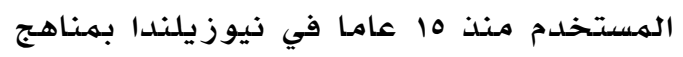
حديثـة أثبتــت نظريــات الـتعلهم المعاصــرة Cues فعاليتها مثل نظريات التعلهم البنائيسة .Constructivist model و استقصت دراســة الصـهمدي (11) بـ الهـرتبـة التي حازتها المغرب في التصنيف الدو لي في

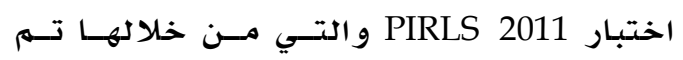
دراسـة وتحليل أسباب حصول الهغـرب على الهى

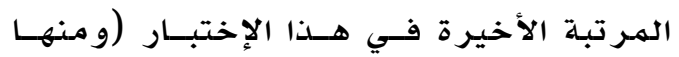

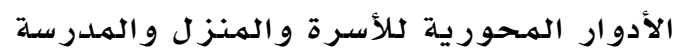
و البيئة المحيطة بالطالب وتطبيقات المناهـج

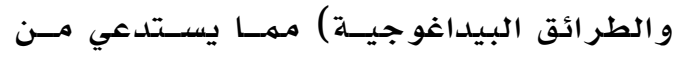

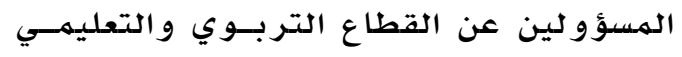

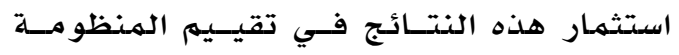

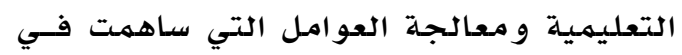
انحدار مؤشرات جودة التعليهم في المغرب. و كما هدفت دراسـة فوي ومارتين وميو ليس

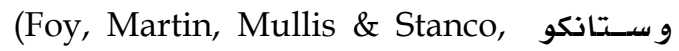
(2011 إلى دراسـة الخصـائص السـيكومترية

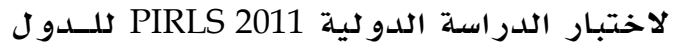

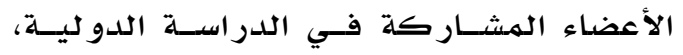

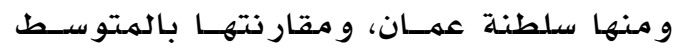
العالهي، و ذلك مـن خلال استجابات الطـلاب

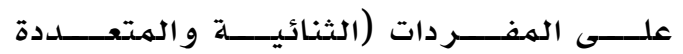
الإستجابة)، ووجد الهف من خلال عـر ض بيانـات

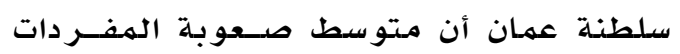

مستوى أداء الأفراد، على الرغم مـن اخـتلاف نوعية الإختبـار ات المستخدمـة و أهدافها. كمـا أن هنــاك العديــــ مــن الدرراســات التــي

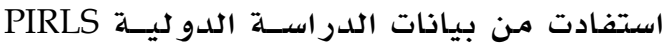

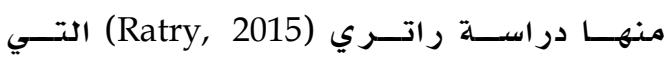
استخلدمت بيانات اختبـار 2011 PIRLS لطــلاب

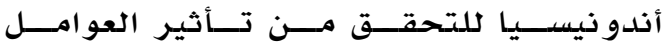

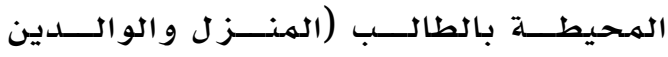

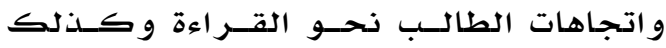

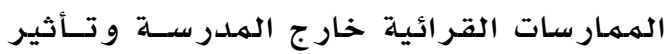
استخدام التقانة و التكنو لوجيا) على المعرفة فئة

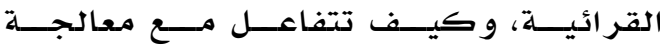

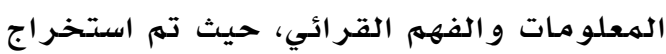

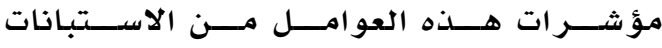

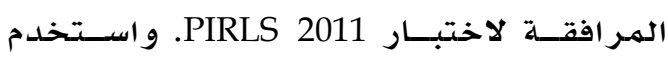
البـاحث نهوذج راش وتحليل الانحدار الخطي

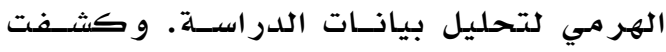

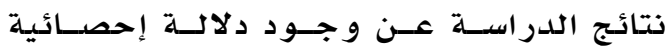

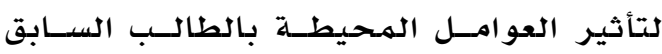

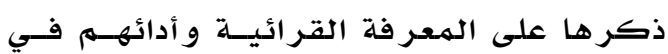

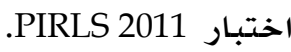

واستخدمت در اسـة زيمـر مسان (

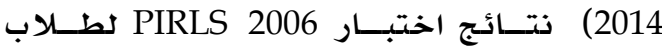
جنوب إفريقيا في الصف الر ابع للوقوف على إنى أسباب تدني مستويات هؤلاء الطلاب وربطهـا بكيفية تدريس الفهـهم القرائـي، مــن خــلال

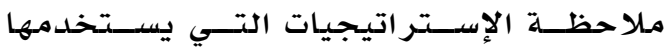
المعلمون فــي تــــريس القــر اءة بشـكل عــام

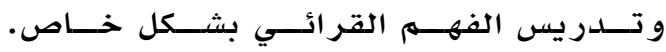

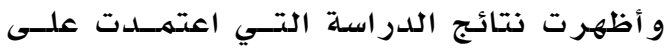

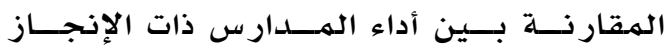

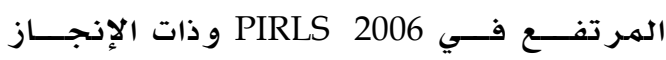

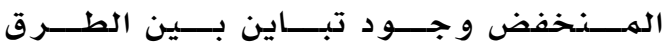
المستخخدمة في تدريس الفهم القر ائسي بــين هذه المدارس، كما كشفت عن وجود فجوة بين أداء المعلمين في الحصة الدراسية وبين

$$
\text { المستوى المطلو بل للفهم القر ائي. }
$$

و سـعت دراســة تـونهـر و تشــابهـن وجر ينـي

و برجنــــــو و آرو ( Chapman, 
المعر فيلة لدى الطلاب وبالتـالي أثـرت علـى

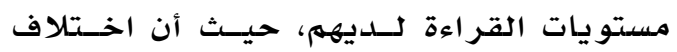
مستويـات الخبـرات لدى الطـلاب أثـرت علـى على مستوى صعو بـة المفر دات.

\section{مشكلة الدراسة}

إن العهل في المجـال التربوي يتطلب تحديـد درجـة معر فـة الطلبــة وإتقـانهم للمهــارات الهـختلفة الهـر اد إكســابهم إياهــا، ووكافـة

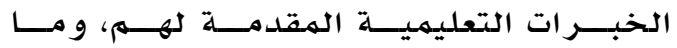
يمتلكون من أنهاط التفكير، و ما يسـتطيعون أداءه من أنشطة ومهام وتكليفات، وركـذلك معررفـة ميــو لههم و اســتعداداتهم و اتجـاهـاتهم نحو القضايا المختلفة؛ وذلك كله مـن أجل اتخاذ قـرارات بشــأن تقــدمهم فـي البــر امـج التعليهيـة و التدر يبيـة و العحلاجية المقدمهة لهم، ومسن ثــم انتقـالهم إلـى مـر احسل تعليهـيــة

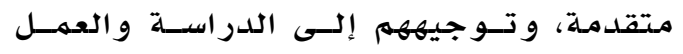

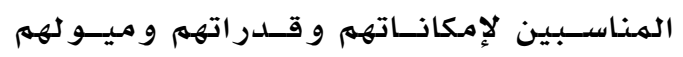
و استعداداتهم، ووكذلك تصنيفهم و المقارنة نـة بينهم. و هذا يتطلب مقاييس في غايـة الدقـة و المووضوعية و الصدق و الحسـاسـية للفـروق الطفيفة بينهه (عبد الوهاب، ·. (r)). ونظرا" لأن النظرية الكلاسيكية تعتهـــ علـى مـجموعة مـن الفر ضيـات البسـيطة و أدت إلـى

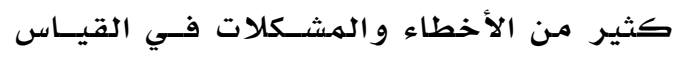
كحصسـول الفـر د علـى نسـبـتين مستلفتـين للذكاء إذا تم اختبـاره باختبـارين مـختلفـين يقيســان الـذكاء؛ وذذلـك لاخـتاكلاف درجـة الخطأ المعيـاري فـي الدحـانتين وتـأثر أداء الفرد على نفس الاختبـار تحت نفس الظروف الاختبـارية إذا أعيد تطبيقه عليه مرة أخرى؛

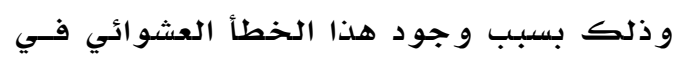
Sijitsma \& , 2006) الدرجة التي يحصل عليها (Junker فـي تحليــل الهفــردات علـى عينـــة الأفــراد المطبق عليهم المقيـاس سـواء عنــد حسـاب الثبــات أو معــامـلات التمييــز أو معـــامـلات

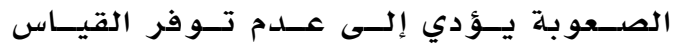

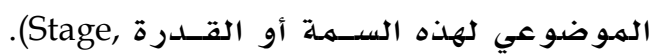
2003; Gleason, 2008)
الثنائية باستخدام نموذج راش تساوي (rV. (.rv)

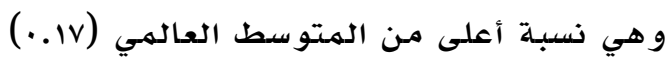

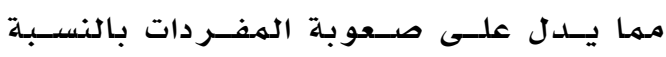
لطلبـة السلطنة, و متو سط صعوبة المفـردات

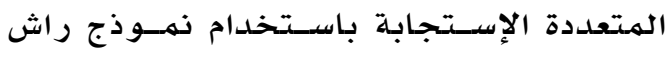
(1.18) وهي أيضا أعلى من المتوسط العالهي

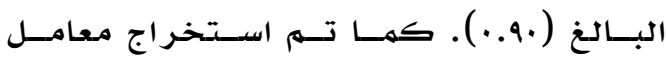
التمـيـيز للهفردات ووجد في بيانـات سـلطنة عمان أن معامـلات التمـيـيـز معـامـلات تميـيـز مو جبـة جيدة و أقـل مــن الهتوس ســ العـالهي

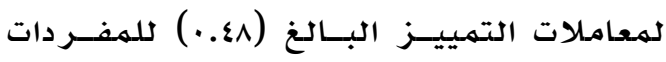
ثنائية الإستجـابة و (الج. .) للهمفردات متعـلددة

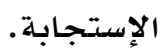

وهـدفت دراســة ميــو ليس ومهـار تيـن وفـوي (Mullis, Martin \& Foy, 2011) من بيانات عس دولـهة فـي اختبـارات اللدراســة الدو لية TIMSS \& PIRLS 2011 للتحقــق مـن العلاقة بين القدرة القرائيـة التي تم قيـاسـها بواســطة اختبـــارات PIRLS 2011 و كـيفيـة تأثيرها على أداء طلاب الصف الرابع في فهم مسدـائل الرياضــيات و العلــوم فـي اختبــار ات TIMSS الطلاب الـذين كـديهم قـدرة قرائيسة عاليـة قـادرون علـى الإجـابـة علـى أســـلة اختبــار و الطلاب الذين لديهم قدرة قر ائيـة مـتدنيــة ســوف تكــون اســتجابتهم أفضـل للهفردات التي لا تتطلب تهكن في القر اءة. أوضحت النتائج صسحة فرضسية الدراسـة أن

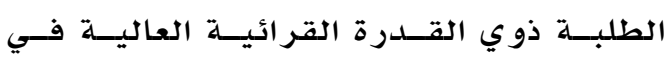
اختبـار PIRLS2011 هم الأفضل في الإستتجابة على جهـيع مفردات اختبـار TIMSS بهـختلفـ

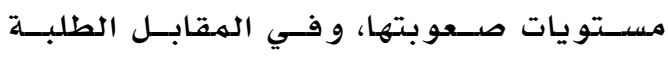
الذين لا يستطيعون القراءة اسـتطاعوا فقــ لكط الإســتجـابـة علــى الهفــردات ذات الصدسعوبـة المتدنية والتي تحتـوي علـى عــدد كلهــات

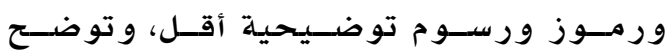

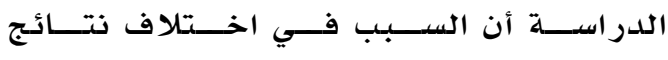
استـجابات الطلاب على الهفـردات يعسود إلـى

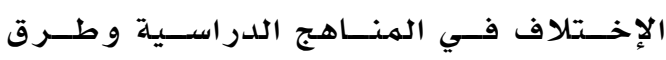
التدريس، والتي لهـا تـأثير علـى المهجـالات 


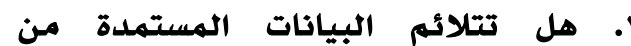
استجابات الطلبة على مفردات اختبار PIRLS2011 الإستجابة المتدرجة المستخدم في مفات تدريج مفردات الإختبار بسلطنة عمان؟ نمان r. ما قيم تقديرات معالم مفردات اختبار PIRLS2011

نموذج الإستجابة المتدرجة بسلطنة عمان؟

؟. ما مقدار المعلومات التي يقدمها اختبار PIRLS2011 لقدرات الطلبة

بسلطنة عمانء

أهمية الدراسة

توجيـه أنظـار العـاملين فـي وزارة

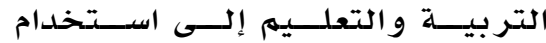

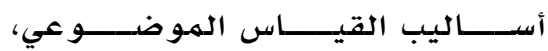

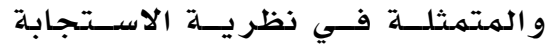
للمفردة ، و الإستفادة مسن خصــائص

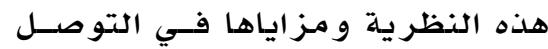
إلى دقة القياس و موضوعيته.

قد تشـجـع هـذه الدراســة البـاحثين على استخدام جميـع نمـاذج نظريـة الإستجابة للمفردة في تدريج اختبار قيـاس مهــار ات القــر اءة (بير لــز ) و المقار نة بينها.

الدراسلة الحالية خطوة للتفاعل مــع التطورات الحيثة في مهال القيـاس الف النفسي و التربوي، و مو اكبتهـا مـن خلال إيجاد الخصائص السيكومترية ولتونية

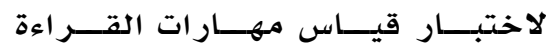
(بيرلز) و معايير تفسـير الأداء فيسي ضوء نظرية الإستجابة للمفردة. قد يفيد تدريج هذا الإختبار في الإكتشاف المبكر للصعوبات التي يعاني منها التلاميذ، مهما يؤدي إلى التى التئ

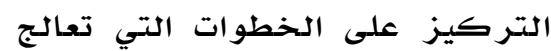

و في الوقت الذي تتعدد فيه عيـوب النظريــة

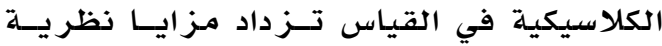

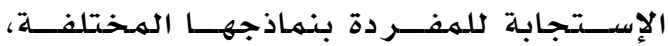
وتتهثل هذه المززايا فـي اسـتقلال خصدسائص

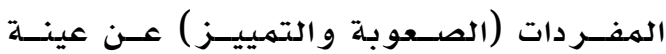

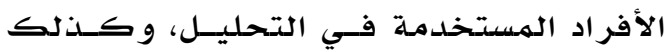

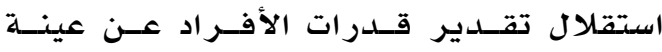
المفردات المكونة للمقياس. كمها أن تفسـير درجات الأفر اد يتم في ضوء الهفردات الهو وليس فـي ضــوء الجمهاعسـة المـرجعيسـة كهــا فـي

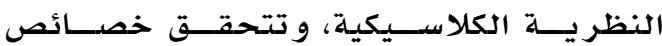
الهيز ان الفتري وربهما القيــاس النسـبـي دون

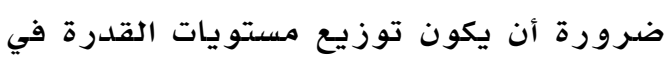

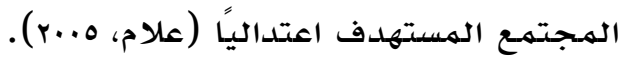
لذذك مـن الههم تـدريج مفـر دات اختبـارات الدر اسلة الدولية (PIRLS) التـي تـهم تنفيـذهـا

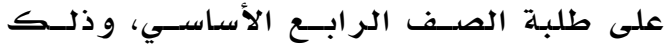
للحصول على تدريج يعطي نتائج تعبـر عـن الحن

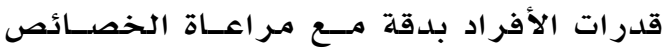

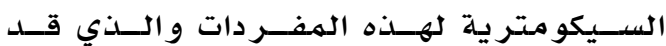

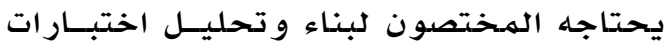

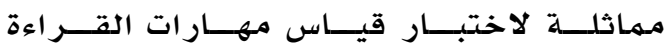

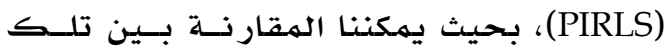
النمـاذج التي تقيس السمـة ذاتها وفقا لمعيـار

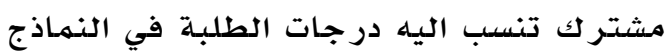
المختلفة مـما يؤدي إلى تقدير ات ثابتــة عــن مستوى تحصيل كل طاسب، بحيـث تتحقـق الدراسلة مـن أن استتجابات الطلبـة على نمـاذج

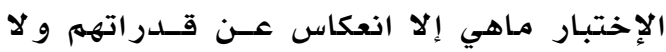

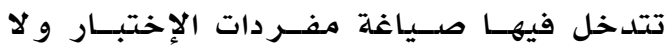
التخمين أو التسـرع في الاجابة، و بالتالي فإن

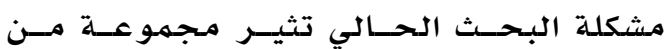
التساؤلات يمكن صياغتها على النحو التالي:

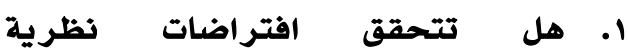

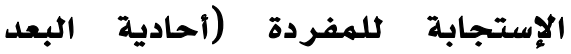

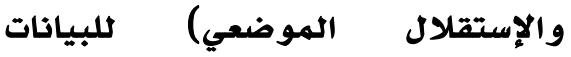
المستمدة من استجابات الطلبة على مفردات اختبار PIRLS2011 بسلطنة عمانو 


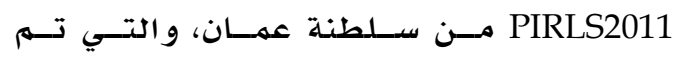

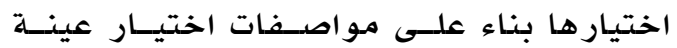

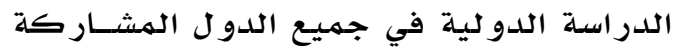

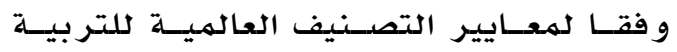

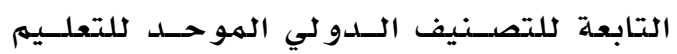

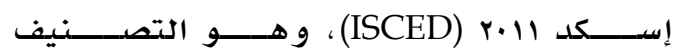

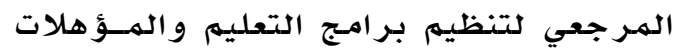

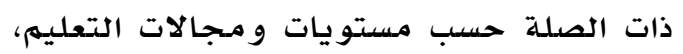
حيث تكونت العينـة من طلبــة الصـف الر ابــع

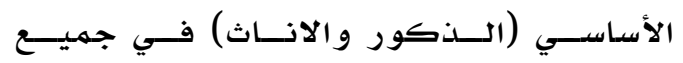

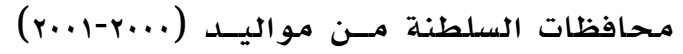
البالغ عددهم عهب.1 و الذين تم إجراء اختبـار PIRLS2011

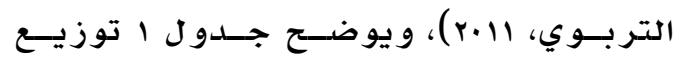

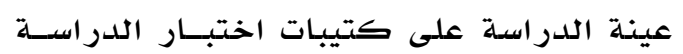
.PIRLS2011

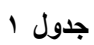

توزيع عينة الدراسة من طلبة سلطنة عمان

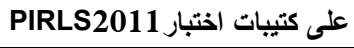

\begin{tabular}{|c|c|c|}
\hline \multicolumn{2}{|c|}{ عدد الطلبة } & \multirow[t]{2}{*}{ رقم الكتيب } \\
\hline ذكور & إناث & \\
\hline roo & $r \leq 0$ & 1 \\
\hline$r \leqslant v$ & rrv & r \\
\hline rot & rr. & r \\
\hline rmo & Mis & $\varepsilon$ \\
\hline ror & $r \varepsilon$. & 0 \\
\hline ror & $r \leqslant 1$ & 1 \\
\hline$r \leq 1$ & ro. & v \\
\hline ro. & $r \leq r$ & $\wedge$ \\
\hline rol & $r \varepsilon$. & 9 \\
\hline rrv & ודוד & 1. \\
\hline rrv & rov & 11 \\
\hline rVT & Mi & ir \\
\hline $1 . \lambda r$ & 1. 1. & Ir \\
\hline OrAN & 01.7 & المجموع \\
\hline
\end{tabular}

أداة الدراسة

اختبار دولي يتكسون مـن ه نصــوص أدبيـة،

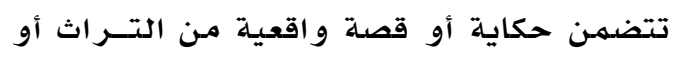

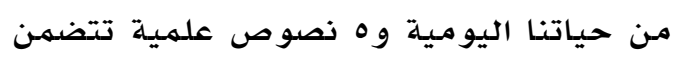

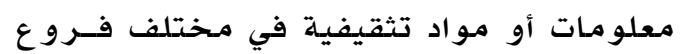

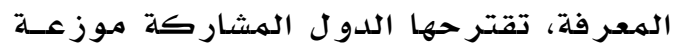

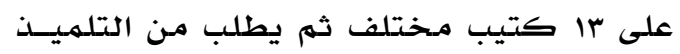

هذه الصعوبات و الوقاية من الوقوع

$$
\text { فيها مستقبلاً. }
$$

مصطلحات الدراسة

نظرية الإستجابة للمفردة: هـي "مـجموعـة من النماذج الرياضية التي تفترض ضله أذه يمكن التنبؤ بسلو ك الأفر اد، أو يمكن تفسير أدير أدائهم في اختبار نفسي أو تربوي معين فـي ضـوء

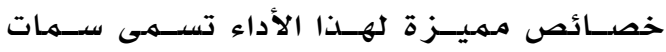
Traits

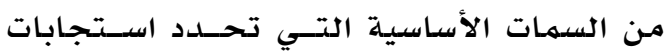

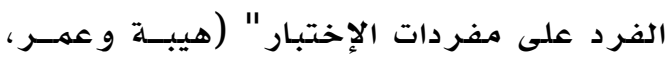

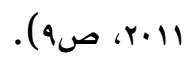

Graded تموذج Response Model

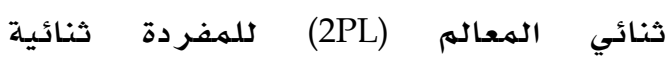
الإستجابة، بحيث يهثل العلاقة غير الخطية بين مستوى قدرة الفرد واحتمال استجابته

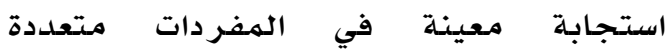

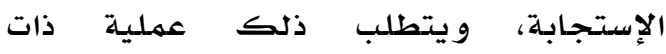
خطوتين من أجل تحديد الإحتمال المشروط لإسل

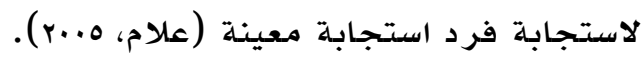
الدراسة الدولية لقياس مدى تقدم القراءة Progress In International Reading (PIRLS) Literacy Study أساس الهقارنة لقياس قدرات طلبة الصف

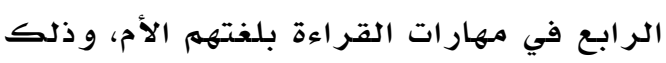

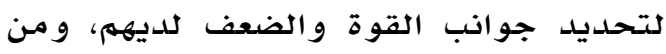
ثم تطوير تلك المهارات والإرتقاء بها، بها

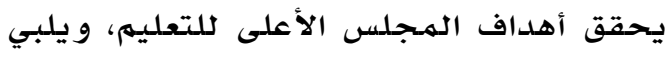
متطلبات تطوير التعليهم في الدولة، ويسهم في تطوير قدرات ووكفايات الطلبة (وزارة

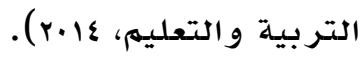

\section{الطريقة والاجر اءات}

\section{مجتمع وعينة الدراسة}

تكون مجتمهع الدراسـة من جميع طلبـة الصف

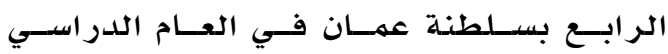

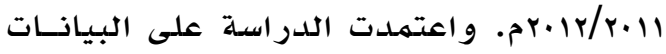

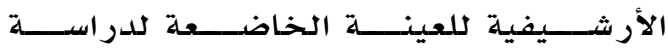


(r). ) وهو بسين نصـي الكتيبـات (1) و (r)،

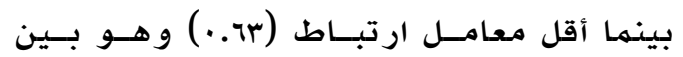

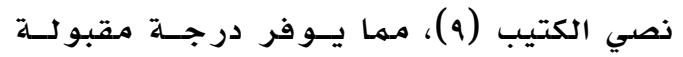
من الصدق البنائي لكل كتيب.

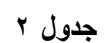

معاملات الارتباط بين نماذج كل كتيب من كتيبات اختبار PIRLS2011

\begin{tabular}{|c|c|}
\hline معامل الارتباط بين النصين & الكتيب \\
\hline 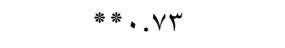 & 1 \\
\hline ***.VI & $r$ \\
\hline$* * . . V r$ & r \\
\hline 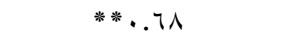 & $\varepsilon$ \\
\hline$* * . .7 \varepsilon$ & 0 \\
\hline$* * \% . . T \mathrm{~V}$ & 7 \\
\hline$* * . .7 \varepsilon$ & $\checkmark$ \\
\hline 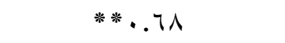 & $\wedge$ \\
\hline$* * .74$ & 9 \\
\hline$\% * .79$ & 1. \\
\hline$* * . .79$ & 11 \\
\hline$* * . .7 \mathrm{~V}$ & ir \\
\hline$* * .79$ & $\pi$ \\
\hline
\end{tabular}

\section{إجراءات الدر اسة}

تم تطبيق كتيبـات اختبـار PIRLS2011 فـي يو م واحد، بحيث يجلس الطلبة لأداء جزئسي الإمتحان في نفس اليوم مـع فتـرة اســتراحة

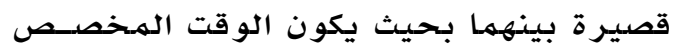

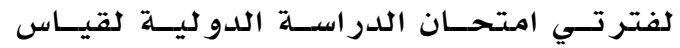

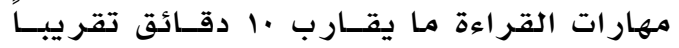
للتحضير للإمتحسان بمـا فـي ذلـك إعـداد

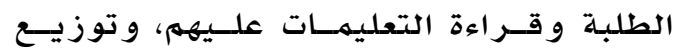
كتيبات الإمتحان، ثم •؛ دقيقة للإجابة علـى

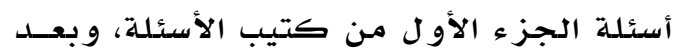

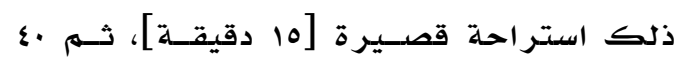

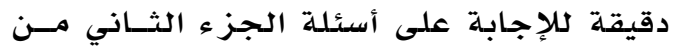

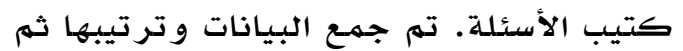

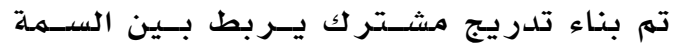

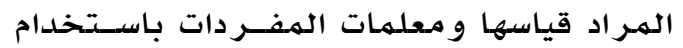

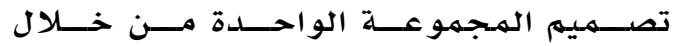

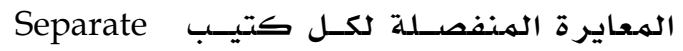
Calibration
قراءة النصين والإجابة عن الأسئلة. وتـوزع

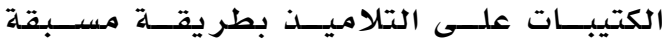

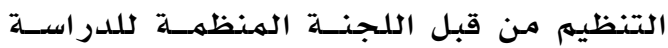
.(Mullis, \& et. al, 2009; Marian \& Jay, 2001 )

يتكـون اختبــار PIRLS2011 بشـكل

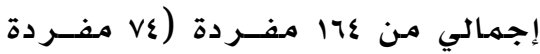

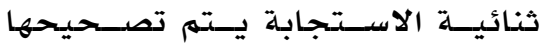

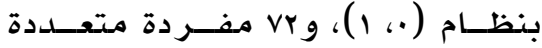

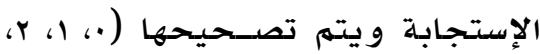

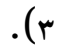

يسـتخدم تصــميهم الكتيبـات تقنيسـة

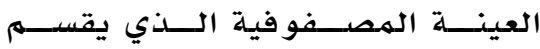

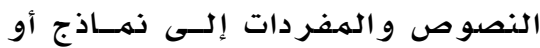
كتل بحيـث يـتم تكسوين كتيبـات

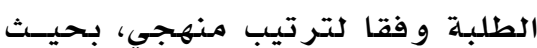
يحتوي كل كتيب على نصين. النصوص الأدبية من (L1 إلى L4) و

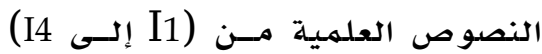

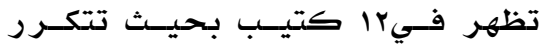
كل منها في r كتيبات، أمـا الــص فئس

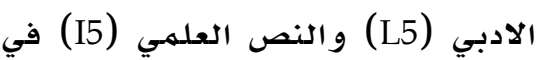
الكتيب (rا) فليست مرتبطة مباشرة

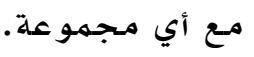

في هذه الدراسة تم اسـتخر اج معامسل ثبـات كل كتيب باستخدام برنامج SPSS بطريقة

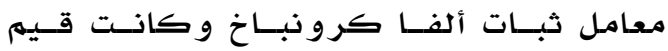

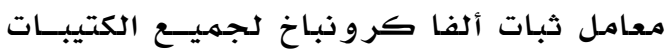

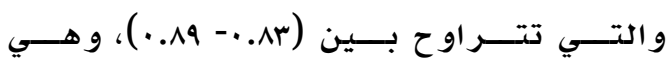

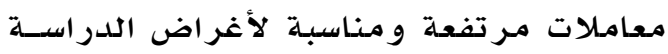

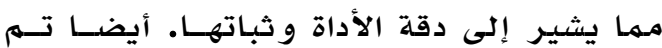
التحقق من صدق الإختبار عن طريق الصدق الصداق

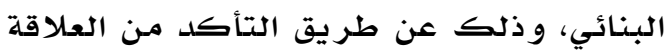
الإرتباطية بين النصين لكل كتيب، و لتحقيق

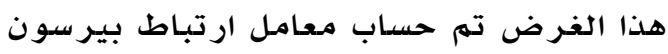
لمعرفة مدى الإرتباط بين النصين في كـل

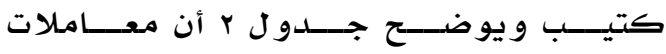
الإرتبـاط بـين النصـين لكسل كتيـب دالــة إحصائيا عند مستوى ال... حيث تتر اوح جسين

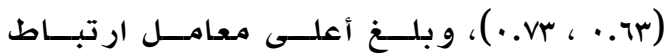




\section{نتائج الدراسة}

إجابة السؤال الأول: هل تتحقـق افتر اضــات

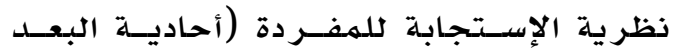

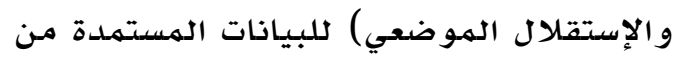

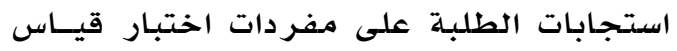
مدى التقدم في القراءة PIRLS2011 بسـلطنة

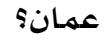
1) التحقق من افتراض أحادية البعد

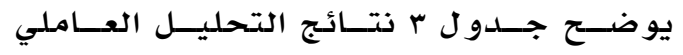

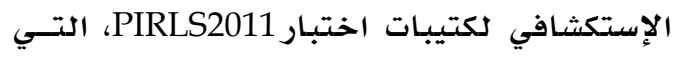

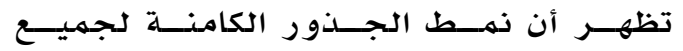

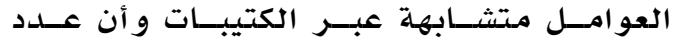
العوامل التـي يمكسن اسـتخراجها باسـتعمال

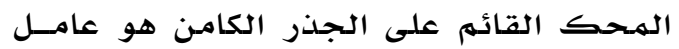

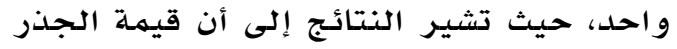

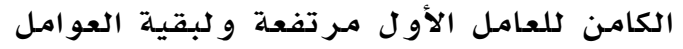

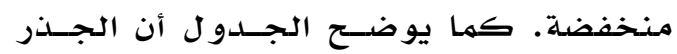
الكامن للعامل الواحد في كل الكتيبات يفسر الكران الجرات

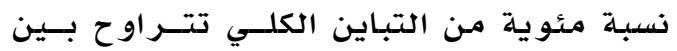

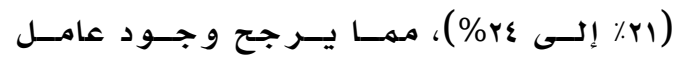

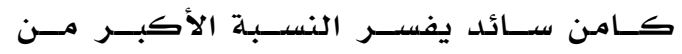
التباين، و نستدل منه على تحقق أحادية البعد

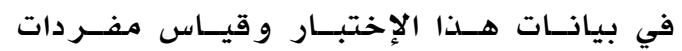
الإختبار لسمة و احدة، وهي السمة التي هدف الإن لقياسها. r r التحقق من الإستقلال الموضعي للمفردات يقصد به أن احتمال الإجابة الصحيحة علىى

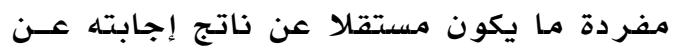

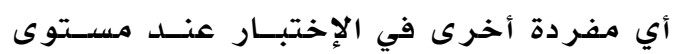

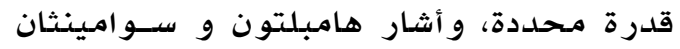

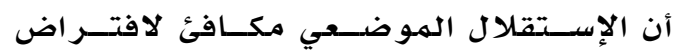

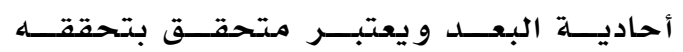

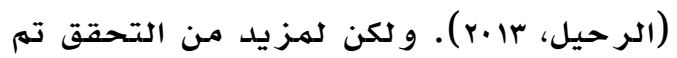

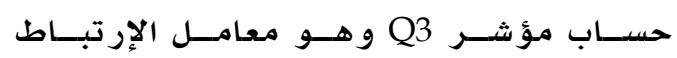
للبو اقي لزوج من المفردات بعد ضبط السمة المقدرة (النعيمي، لزوب من المفردات
نظرية الإستجابة للمفردة (افتر اض أحاديسة

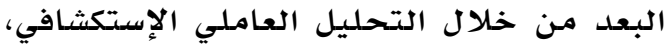

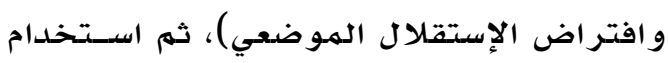

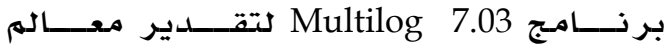

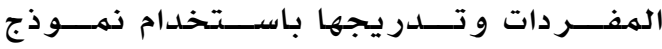

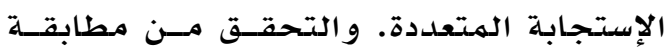

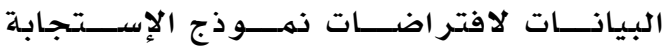

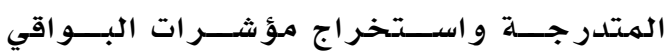

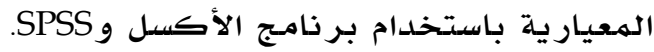

المعالجة الاحصائية

للإجابة عن التساؤل الأول تم إجراء التحليل

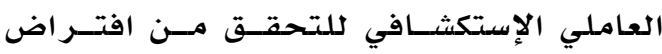

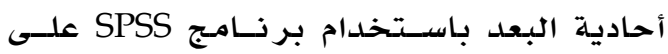
إجابات أفراد عينة كل كتيب على المفردات بات المات

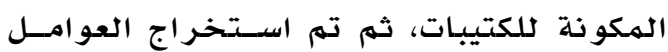

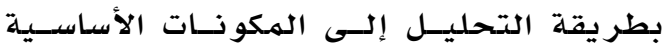

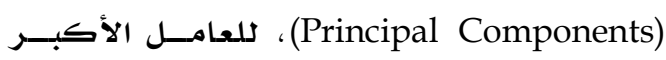
من الواحد الصحيح، كما تم حساب معاملات

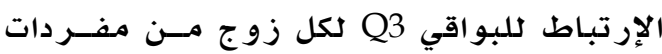

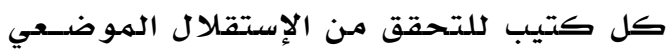
للمفردات. كمها تهـت الإجابـة عـن السـؤَال

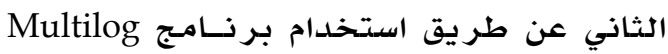

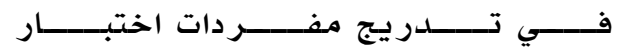

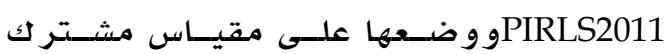

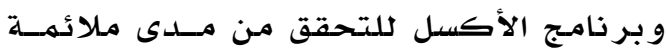

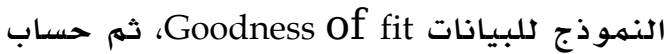

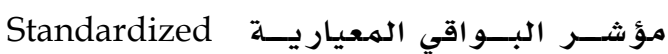

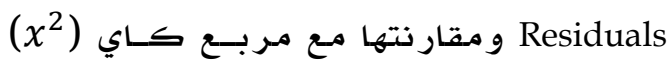
كمؤشر لحسن مطابقة المفردات أو الأفراد

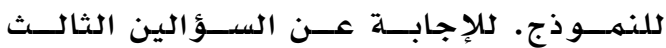

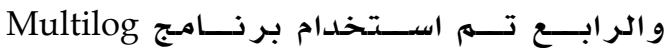
لاستخراج تقدير معالم المفردات (الصسعوبة

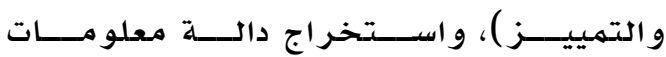

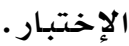


جدول r

نتائج التحليل العاملي لكتيبات PIRLS2011 للتحقى من أحادية البعد

\begin{tabular}{|c|c|c|c|c|c|c|c|}
\hline نسبة التباين المفسر & الجذر الكامن & العوامل & الكتيب & نسبة التباين المفسر & الجذر الكامن & العوامل & الكتيب \\
\hline rT.VT & $7.1 \mathrm{~V}$ & 1 & r & $r \leq . \varepsilon r$ & 7.11 & & 1 \\
\hline ¿.V. & $1 . K Y$ & $r$ & & 0.19 & $1 . r$. & & \\
\hline$\{. \leqslant 7$ & 1.17 & r & & 纟.Tr & 1.10 & & \\
\hline r I. $\leqslant 9$ & $7 . \wedge 1$ & 1 & $\varepsilon$ & rr.rq & $V .9 Y$ & & $r$ \\
\hline $0 . r \Lambda$ & $1 . V r$ & $r$ & & ¿.V. & 1.09 & & \\
\hline س. & $1 . \leqslant \wedge$ & $r$ & & ¿.r. & $1 . \leqslant V$ & & \\
\hline rY.rq & $0 . r \Lambda$ & 1 & 7 & r1.01 & 0.11 & & 0 \\
\hline 0.19 & $1 . r 0$ & r & & $0 . \Sigma V$ & 1.41 & & \\
\hline$\varepsilon . \wedge 7$ & $1.1 \mathrm{~V}$ & r & & $\varepsilon .90$ & 1.19 & & \\
\hline Yะ.TY & $V . \cdot V$ & 1 & $\wedge$ & YT.11 & $7 . Y 1$ & & V \\
\hline 0.90 & $1 . V r$ & $r$ & & $7 . .0$ & 1.79 & & \\
\hline E.Yo & T. & $r$ & & $\varepsilon . \vee q$ & $1 . r \varepsilon$ & & \\
\hline$r \varepsilon . \leqslant r$ & 0.17 & 1 & 1. & YI.AV & $0 . \leqslant V$ & & 9 \\
\hline 0.19 & 1.50 & r & & $0 . V V$ & $1 . \leqslant \varepsilon$ & & \\
\hline$\varepsilon . \wedge \varepsilon$ & 1.17 & r & & $\varepsilon .10$ & 1.41 & & \\
\hline r..q. & $\lambda . r \leq$ & 1 & IT & r.r.rq & $0 . \wedge r$ & & 11 \\
\hline 0.10 & T..VV & r & & $0 . Y 7$ & $1 . r v$ & & \\
\hline \multirow[t]{4}{*}{$\varepsilon . T \varepsilon$} & 1.04 & r & & \&.人T & $1 . r V$ & & \\
\hline & & & & rT. $\varepsilon T$ & A.r. & & 14 \\
\hline & & & & 0.74 & $1.9 \mathrm{~V}$ & & \\
\hline & & & & ๕.9. & $1 . V T$ & & \\
\hline
\end{tabular}

بمتو ســط مقــداره (1...)، مـاعـدا الكتيـبـ

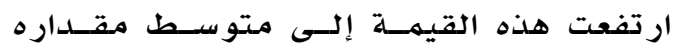

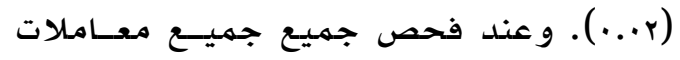

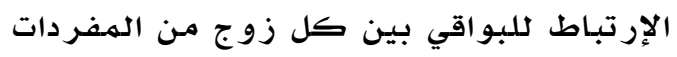

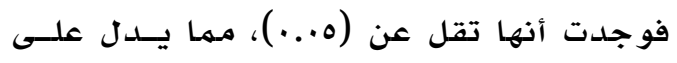

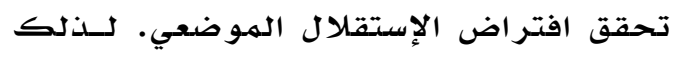

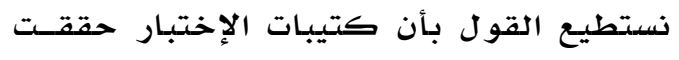

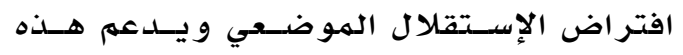

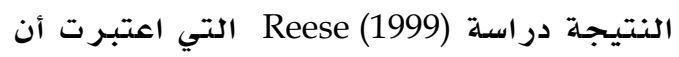

و يوضـح جـدو ل ع متوسط مؤشــر Q3 لكـل

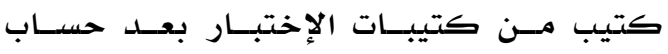

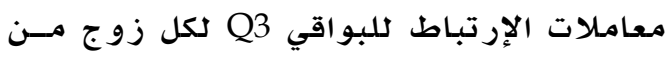
مفردات كل كتيب. حيث أثـارت النتــائج فـي جــدو ال ع إذـى أن افتر اض الإستقلال الهوضعي قد تحقـق فـي

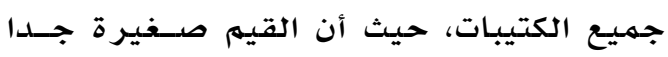
فكانت أقل هذه القيهم عند جميـع الكتيبات جدول

متوسط مؤشر Q3 عند كل كتيب من كتيبات الإختبار

\begin{tabular}{|c|c|c|c|c|c|}
\hline منوسط Q3 & عدد المفردات & رقم الكتيب & منوسط Q3 & عدد المفردات & رقم الكتيب \\
\hline$\cdots 1$ & rq & $\wedge$ & $\cdots \cdot 1$ & ro & 1 \\
\hline$\ldots 1$ & ro & 9 & $\cdots \cdot 1$ & r & r \\
\hline$\ldots 1$ & $r \varepsilon$ & 1. & $\ldots+1$ & $r \varepsilon$ & r \\
\hline$\ldots 1$ & ז & 11 & $\cdots \cdot 1$ & r & $\varepsilon$ \\
\hline$\ldots 1$ & דr & ir & $\ldots 1$ & $r \varepsilon$ & 。 \\
\hline \multirow[t]{2}{*}{$\cdots 1$} & ro & r & $\cdots \cdot 1$ & $r \varepsilon$ & 7 \\
\hline & & & $\ldots r$ & r^ & v \\
\hline
\end{tabular}


حيث يتضــح مطابقـة البيانـات مــع توقعـات

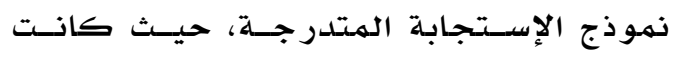
قيمـة مؤشر كل كتيب غير دالة مقارنة مـع

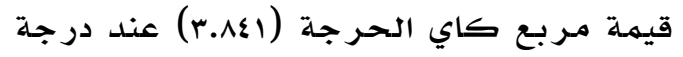

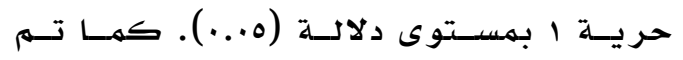
التحقق مـن مـلاءمـة المفردات للنهــوذج كـل بهل

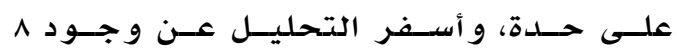

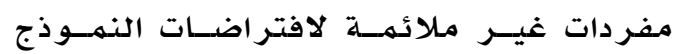

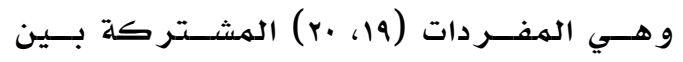

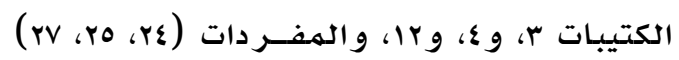

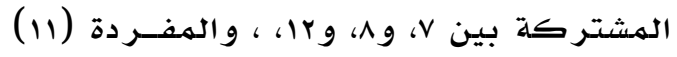

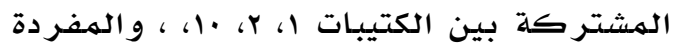

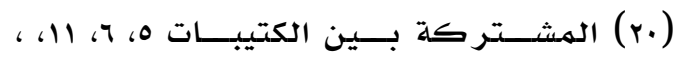
و يمكن أن يعود عدم ملاءمة هـذهـ المفــردات

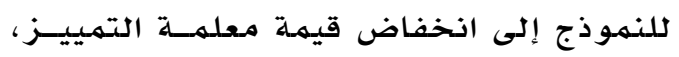

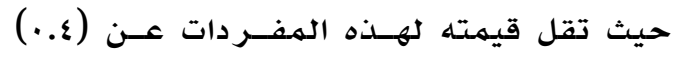
مـما يدل على أن هذه المفـردات غيـر قــادرة

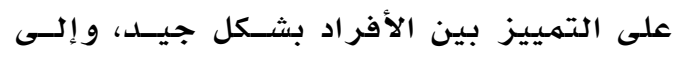
ارتفاع قيم معلمة الصعوبة التي تتراوح بين

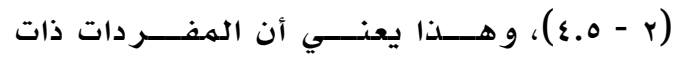

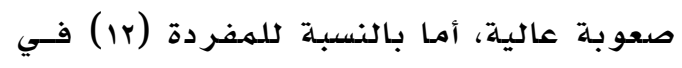

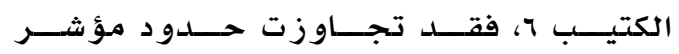

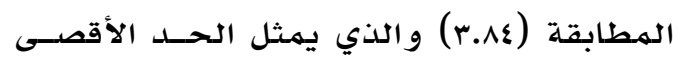

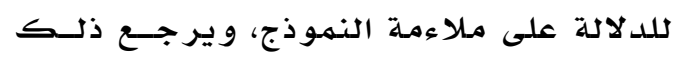

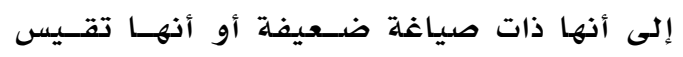

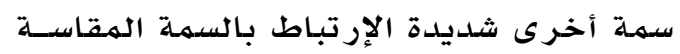

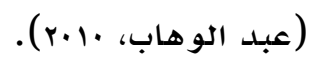

كما تم التحقق من مطابقة الأفر اد للنهموذج

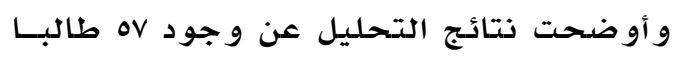

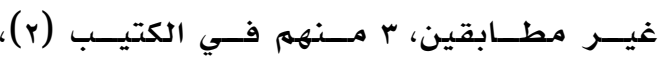

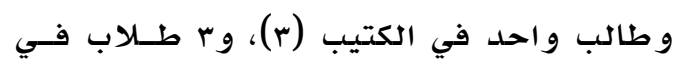

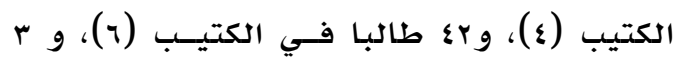

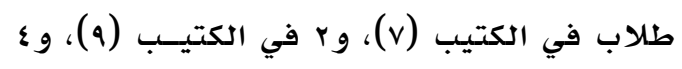
طلاب فـي الكتيـب (11)، حيسث كانـت قـيم

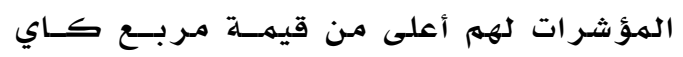

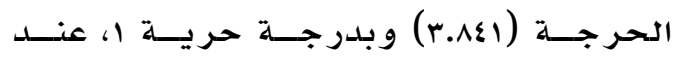

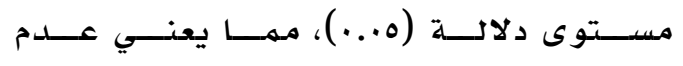

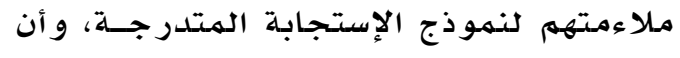

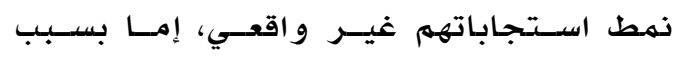

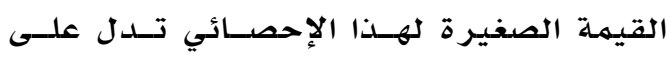
كفاءته في الكشف عن الإستقلال الهوضـعي،

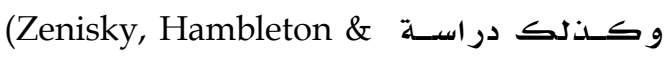
Sireci 2002)

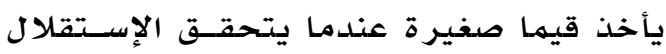
الموضعي لهفردات الإختبار . لمان

إجابة السؤال الثــاني: هـل تـتلائم البيانـات الهستمدة مـن استجابات الطلبـة على مفــردات

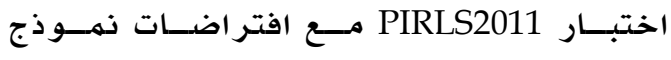

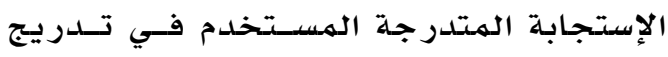
مفردات الإختبار بسلطنة عمان؟ الهم كلإجـابة عن هذا السؤال تم استخدام برنـامـج PIRLS2011 لتدريج مفردات اختبار Multilog وو ضـعهها علــى مقيــاس مشــتر ك، وبر نـامـج

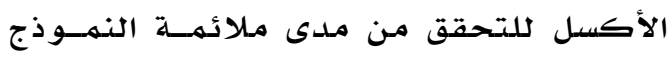
للبيانات، حيث أن تقدير معالم نموذج معسين

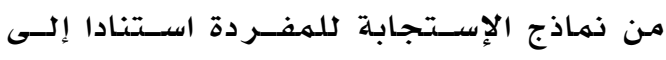

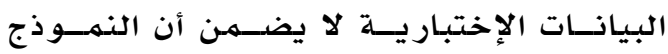
يطابق هذه البيانات، فلا يمكن الإستفادة مـن

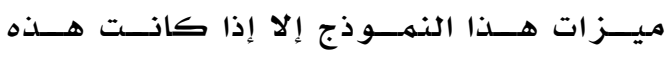

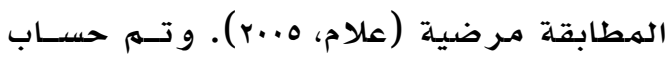

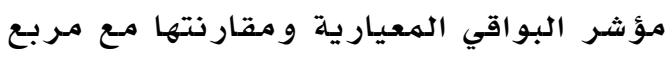

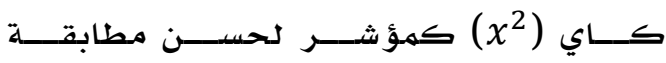
المفردات أو الأفراد للنموذذج، ويوضسح جدول

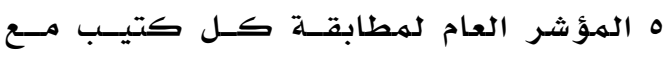

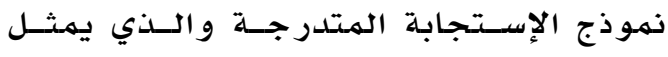

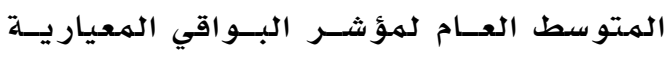
للهمفردات.

\section{جدول}

المؤشر العام لمطابقة النموذج لمفردات اختبار

PIRLS2011

\begin{tabular}{|c|c|c|c|}
\hline المؤشر & رقم & المؤشر & رقم الكتيب \\
\hline..$\wedge 1$ & $\wedge$ &.$\wedge 7$ & 1 \\
\hline..$\wedge 7$ & 9 &.$\wedge 0$ & r \\
\hline..$\wedge 9$ & 1. & $\cdot . \wedge \Lambda$ & $r$ \\
\hline.$\wedge 0$ & 11 & I.r & $\varepsilon$ \\
\hline . .Ar & IT & $\cdot \wedge \varepsilon$ & 0 \\
\hline \multirow[t]{2}{*}{ 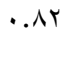 } & r &.$\wedge 7$ & 7 \\
\hline & &.$V V$ & V \\
\hline
\end{tabular}


كتيبات اختبار PIRLS2011 حيث يتضـح أن قيهم صعوبة مفردات كل كتيب تغطي مــى واسعا من الصعوبة وإن كانت تميـل بصدفة عامة إلى أن تكون مفردات مـرتفعة الصعوبة

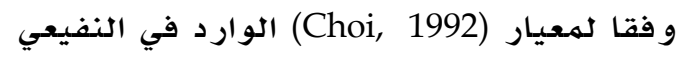

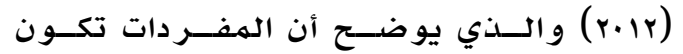

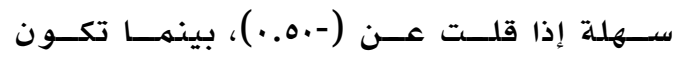

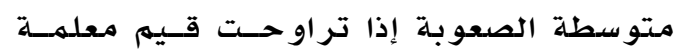

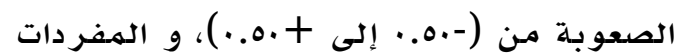
تكون صعبـة إذا كانت قيم معلمــة الصـعوبة إنه

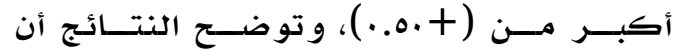

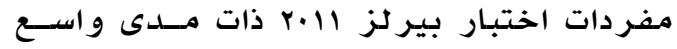

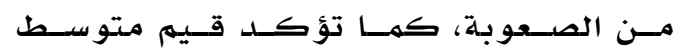

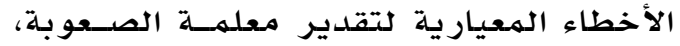

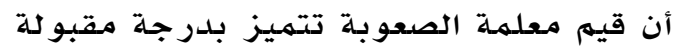
من الدقة و الثبات في تقدير ها.

تم تقدير معلمسـة تمييـز مفـردات كتيبـات

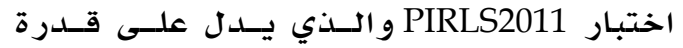
مفردات الإختبـار على التمهييز بوضـوح بـين

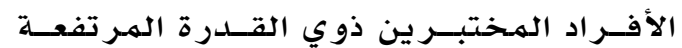

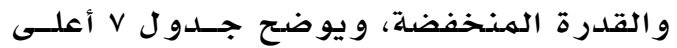
و أقل قيمة لمعله التمييز في كل كتيب من المدئ كتيبات الإختبار .

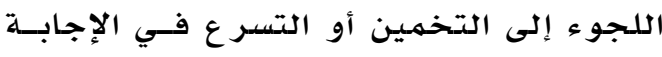

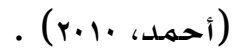

إجابة السؤال الثالث: ما قيم تقديرات معاله

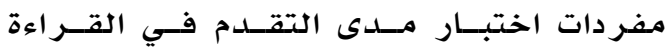

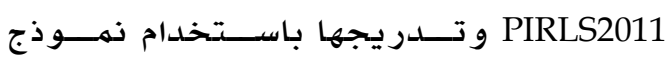
الإستجابة المتدررجة بسلطنة عمان؟ تم تقدير معالهم مفردات اختبار مهارات مدىى التقـــدم فـي القــر اءة PIRLS2011 بـاســتخدام نهـوذذج الإســتجابة المتدررجسة وتسهم تقــدير

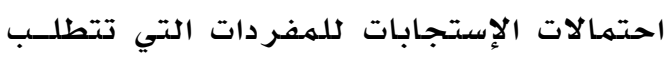
استجابات متتدرجــة، والتــي تتضــمن حســاب منـحنيات بعدد يسـاوي عدد العتبـات الفارقـة لكل مفردة. كما تم تقــدير معسالم الصـعوبة للهفـردات

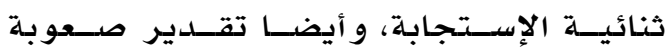
الهفردات متعددة الإستجابة عن طريق حساب متوسط قيه العتبات، حيث تشير هذه الهعالم

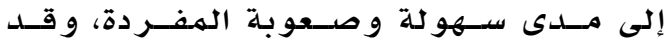
اختلفت قيهم معلمسـة صدعوبة المفسردات مسن

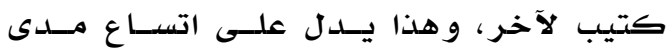

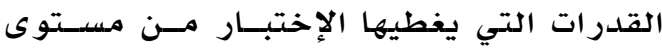
القدرة المسنـخضض إلـى المســتوى المـرتفــع،

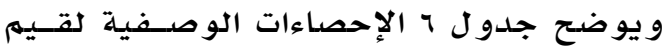

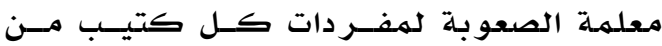
جدول 1

الإحصاءات الوصفية لقيم معالم الصعوية لمفردات كتيبات الإختبار

\begin{tabular}{|c|c|c|c|c|c|}
\hline الاتحراف المعياري & المتوسط الحسابي & أصغر صعوبة & أكبر صعوبة & عدد المفردات & الكتيب \\
\hline. .14 &.$V r$ & $.77-$ & r.rq & ro & 1 \\
\hline. $.1 V$ & $.7 \varepsilon$ & $1.00-$ & r.9V & ז & r \\
\hline.$r$ & .110 & $\cdot .77-$ & T.OT & $r \varepsilon$ & r \\
\hline 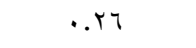 &. .99 & $\because \vee \wedge-$ & r.Ar & rt & $\varepsilon$ \\
\hline . rr & $1 . . v$ & $\cdot . \wedge V_{-}$ & T.YO & $r \varepsilon$ & 。 \\
\hline.$r$ &.$\vee \wedge$ & $\cdot r V-$ & r. $9 \mathrm{~V}$ & $r \varepsilon$ & 7 \\
\hline.$r V$ &.$\wedge \vee$ &.$r \Lambda_{-}$ & r.97 & rA & v \\
\hline .17 &.$V T$ & .ro- & T.ro & rq & $\wedge$ \\
\hline$\cdot r_{1}$ & $1 \ldots$ & $.90-$ & $T . V \varepsilon$ & ro & 9 \\
\hline מזים &.$\vee 99$ & $1 . . \leqslant-$ & $\varepsilon .09$ & $r \varepsilon$ & 1. \\
\hline .11 & $.9 r$ & $.19-$ & Y.TI & r & 11 \\
\hline$. T \leq$ & $1 . .7$ & $\cdot . \leqslant 0-$ & T.ะ. & די & ir \\
\hline. .14 & $1.1 \varepsilon$ & .rq- & r. $9 \mathrm{~V}$ & ro & 14 \\
\hline
\end{tabular}


ذلك شكل ا (ملحق 1) الذي يعرض منحنسى (تصن

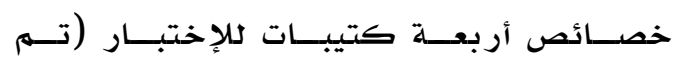

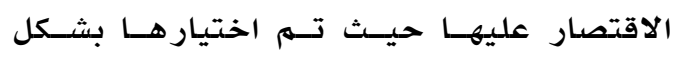

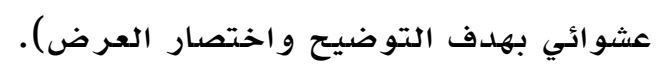
إجابة السؤال الرابع: ما مقدار المعلومات التهات

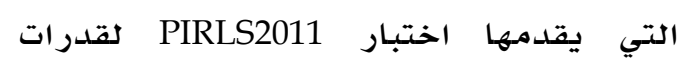
الطلبة بسلطنة عمان؟

تم استخر اج منحنى معلو مات الإختبار الإختيار Information Curve)

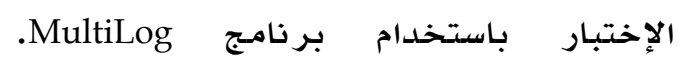

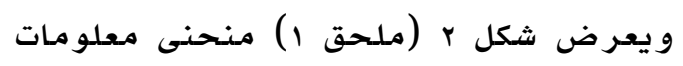

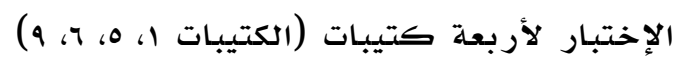

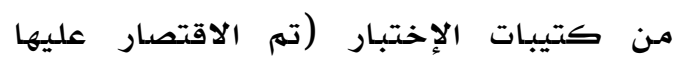

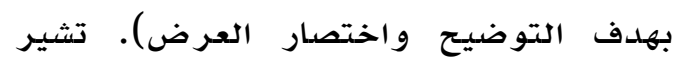

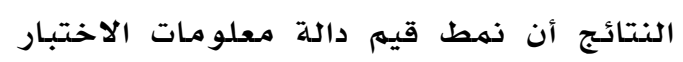

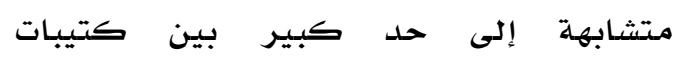

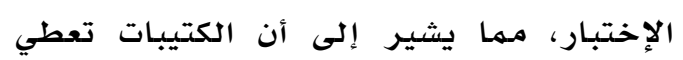

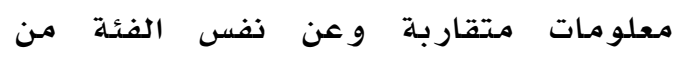
الطلاب، مـع وجود اختلافات بسيطة بينها، متئل

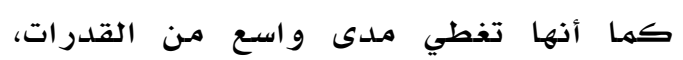

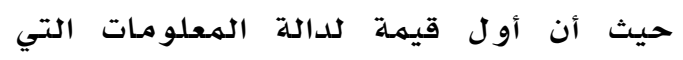

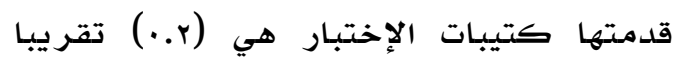

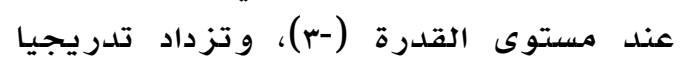
بتزايد مستوى القدرة لتصل إلى أعلى أعلى

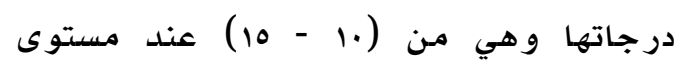

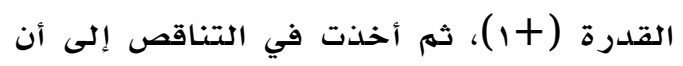

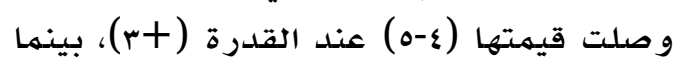

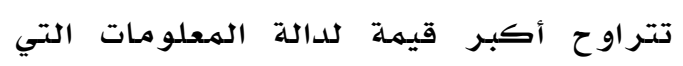

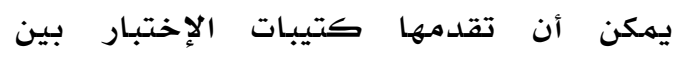

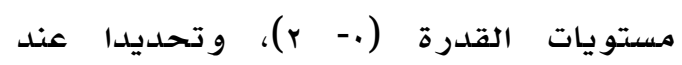

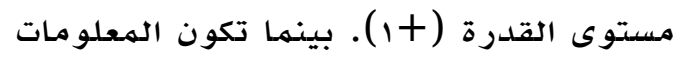

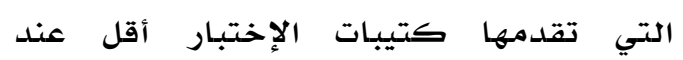

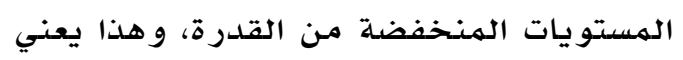

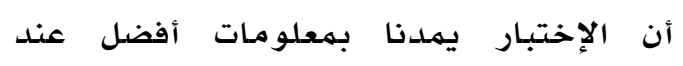

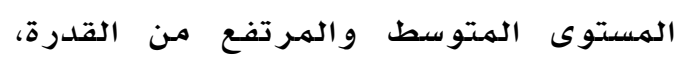

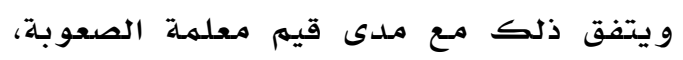

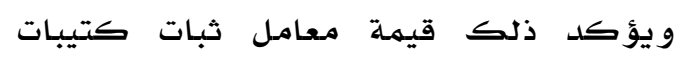

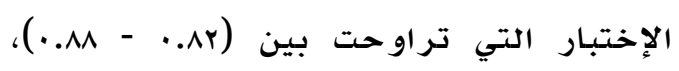

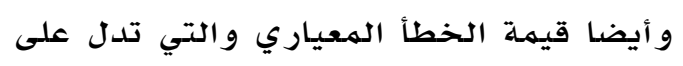
دقة القياس والتي بلغت أخطا المعياري والتي تدر دراتها

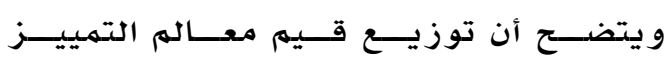

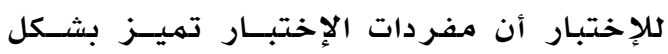

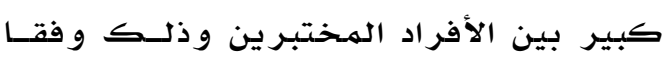

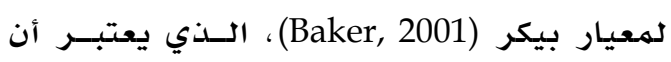

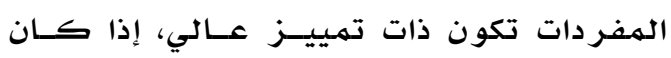

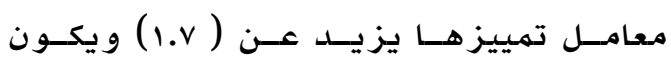

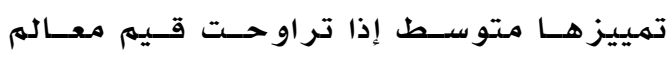

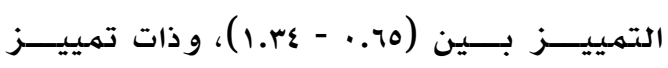
منخفض إذا تر اوحت قيم معالم التمييز بـين

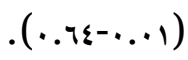
جدول

\begin{tabular}{|c|c|c|}
\hline أقل كتيبمة اللتمييز & أعلى قيمة للتمبيز لمئم التميزز & أكتى وأ \\
\hline . & r.Or & 1 \\
\hline . 01 & r.\& & $r$ \\
\hline דז.. & r.VV & $r$ \\
\hline. Y个 & $\varepsilon . r v$ & $\varepsilon$ \\
\hline Tr. & 1.9. & 0 \\
\hline .01 & r.l. & 7 \\
\hline ת & r.A & v \\
\hline $.0 \leqslant$ & 0.14 & $\wedge$ \\
\hline הז. & r.11 & 9 \\
\hline . TV & 1.94 & 1. \\
\hline r & r.ro & 11 \\
\hline דז.. & r... & Ir \\
\hline .00 & r.Ar & Ir \\
\hline
\end{tabular}

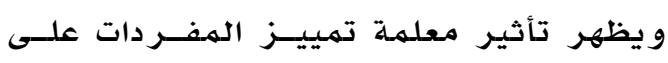

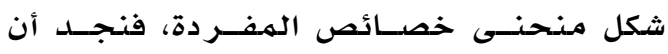

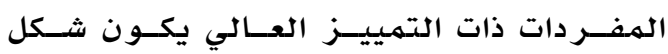

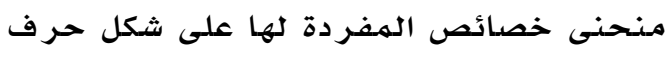

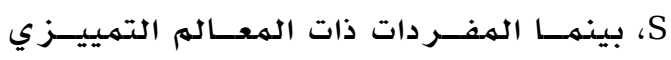

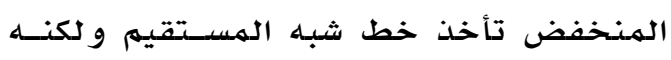

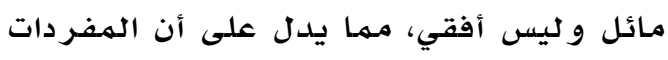

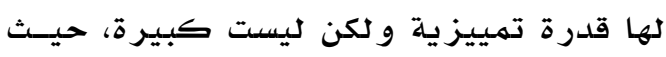

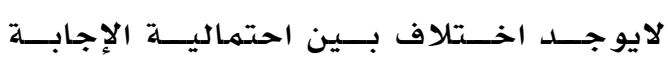

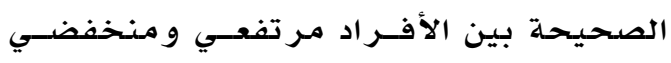

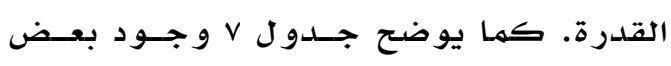

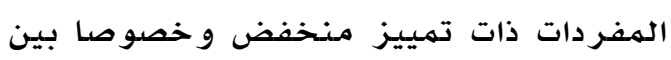

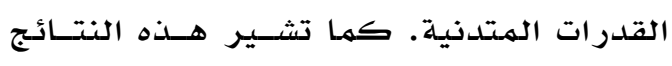
إلى تمتع بعض مفردات كتيبات القدرات العتدنية

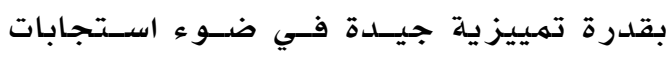

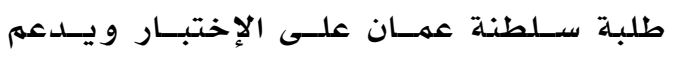


المفردة بالهفردات التـي تتبعهـا فـي الإنيا

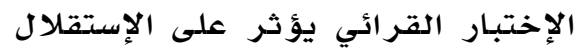

$$
\text { الموض ضعي. }
$$

ع. صدق محتوى الإختبار من حيث تكافؤ

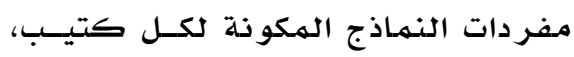

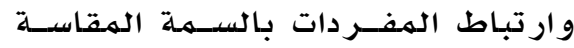

(القر اءة).

و وتتفق نتائج السؤال الاول مـع نتـائج العديــد

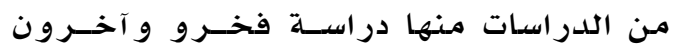

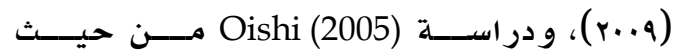

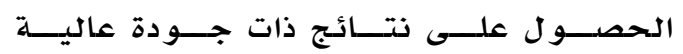

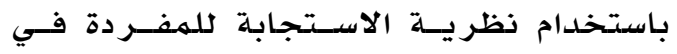

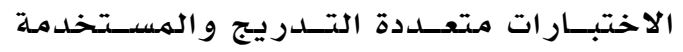
لأغر اض التحليل، و يمكن الإستفادة من هــــه

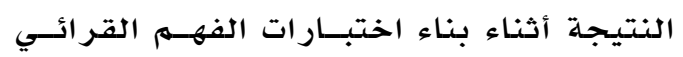

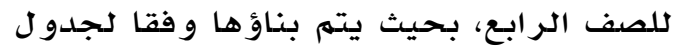

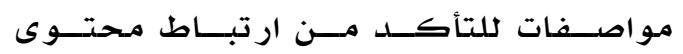

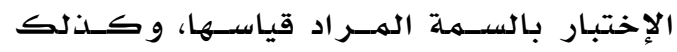

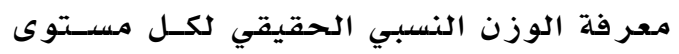

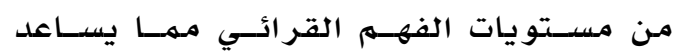
المعلم على توزيع المفردات حسب أهميتهـا، و يكسب الطالب ثقة كبيرة بعدالة الإختبار. كما أشارت النتائج إلى وجود حسن مطابقة

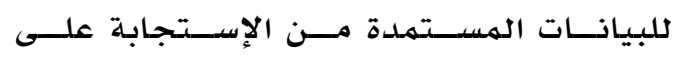

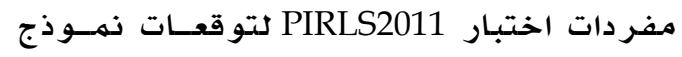

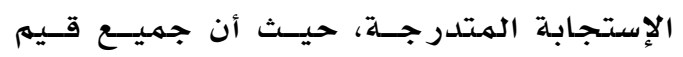
مؤشر البواقي المعيارية غير دالــة إحصـائيا،

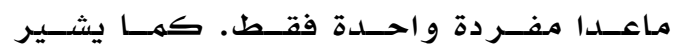

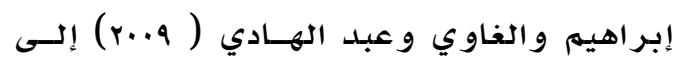

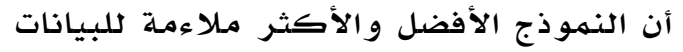

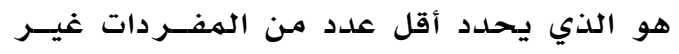

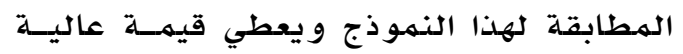
للثبات، و من ثم يمكن القول بأن هذئ لهذا الإختبار

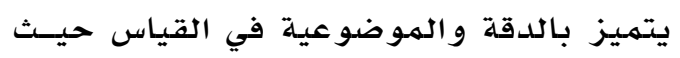
يتصـف بخصــائص سـيكو مترية جيسـدة لكسل

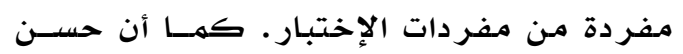

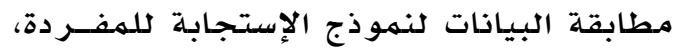
يوضح قدرة هذا النهوذج على تفسير بيانـات

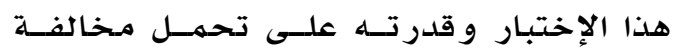

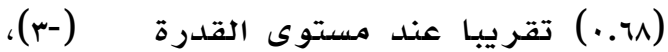
وتتناقص تدريجيا لتصل إلى أقل قيمة لها لها

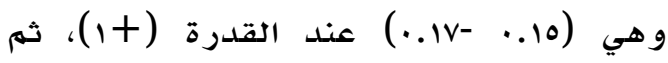

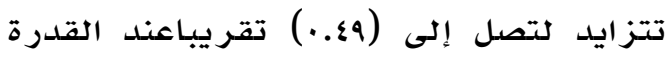

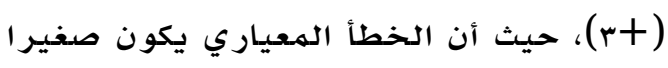

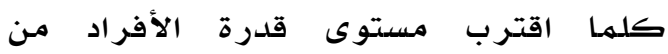

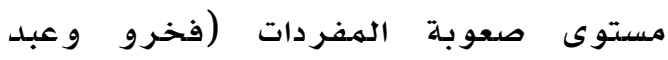

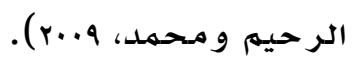

المناقشة والاستنتاجات

تناولست هـــه الدراسـة تفحس الخصــائص

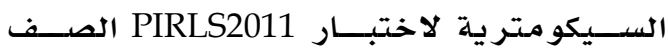

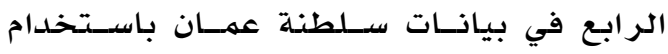

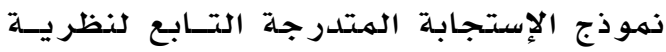

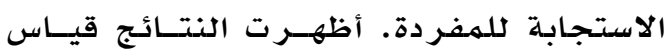

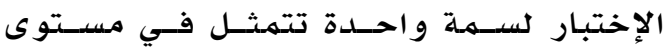

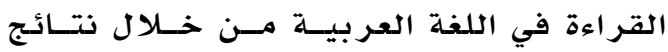

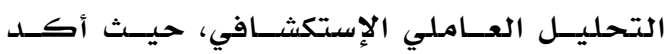
Ackerman

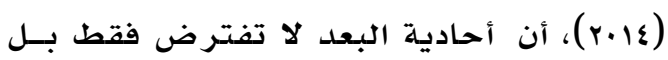

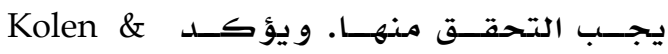

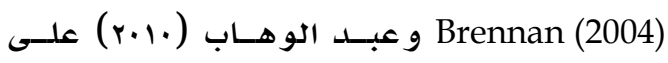
وجود عامل أو مكون واحسد مسـيطر يكمـن

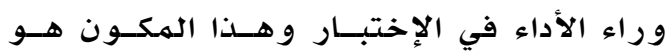

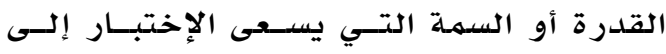

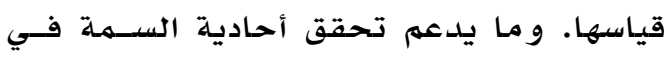
اختبار PIRLS2011 تميز بيانات هذا الاختبار

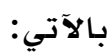

ا. الصياغة الجيدة للمفـردات بحيـث لا

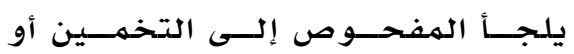

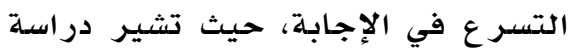

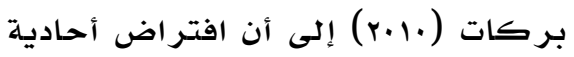

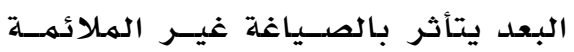

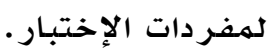
r. إعداد الإختبار وفقا لجدول مواصفات

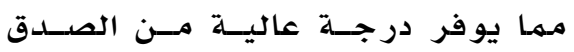

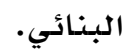

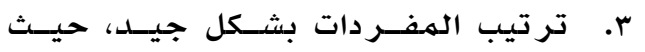

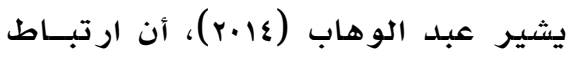


مهـارات القـر اءة (PIRLS) الـذي يسـعى إلـى

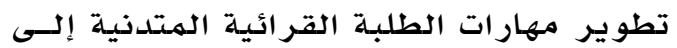

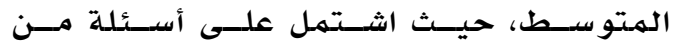

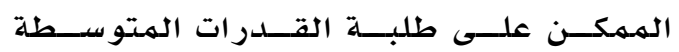

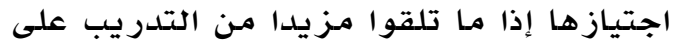

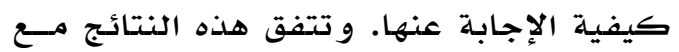
در اسـة (Foy \& et. al, 2011) و در اســة ( Mullis (\& et. al, 2011

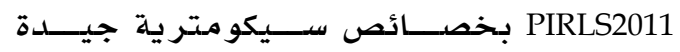
وقادرة على إعطاء مؤشرات دقيقة عن قدرات

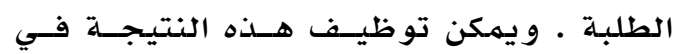

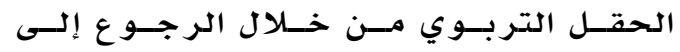

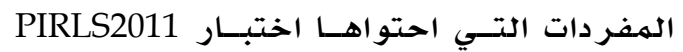

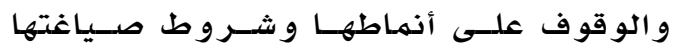

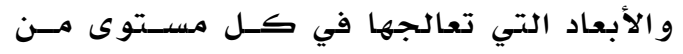
مستويات الفهم القر ائي ثم إيجاد استر اتيجية

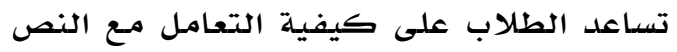

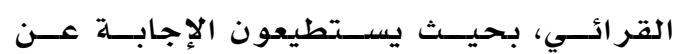
المفر دات بهـتلف مستو ياتهم.

التوصيات و المقتر حات

تقدم الدراسة في ضــوء نتائجهــا التوصـيـات

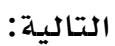

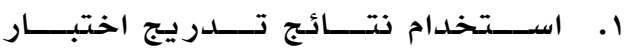

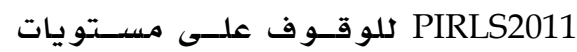
طلبة الصف الر ابع في الفهم القرائـي

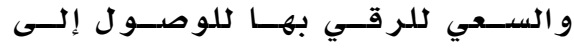
المستوى المطلوب.

r. استخدام نتائج تقدير ات معالم مفردات

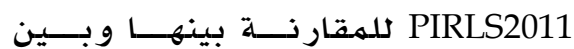
معالم المفردات التي يتضمنها المــهـج

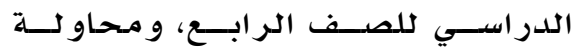

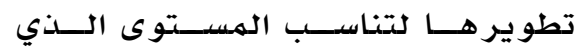

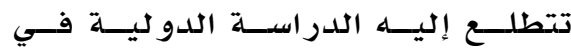
و صول طلبـة الصف الر ابع إليه.

r. استخدام نتائج الدراسلة في بناء بنــك لهفــردات اختبـــار PIRLS باعتبــــاره يتصف بخصائص سـيكومترية عاليسة، مما يسهل الرجوع إليها و توظيفها في لئي

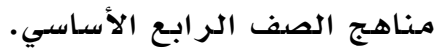

بعض افتر اضــاته بحيـث لا لــؤثر فـي دقـة تقدير ات المعالم.

كما أن مطابقة المفردات للنموذذج يدل على الهم

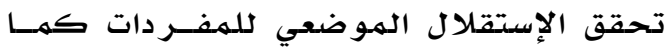

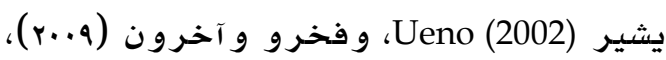

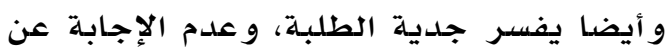

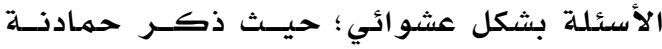

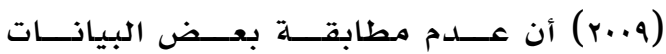

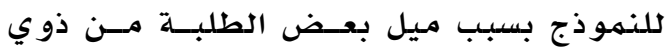

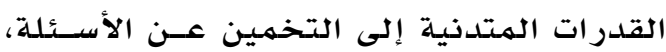
وكذلك إخفاق الطلبـة ذوي القدرات العالية

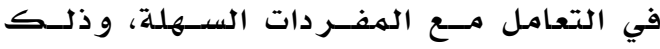

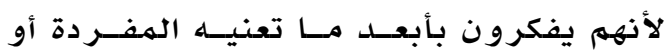
أنهم يميلون إلى تفسير المفردة بأكثر مهما

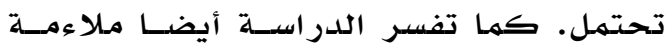
البيانــات للنـمــوذ ج بســبـب وقــوع معــالم المفردات ضمن المدلى المقبول حسب توقعات النمـوذج، و كذلك ارتباط هذه المفردات مـع بعضها البعض في قياسها للقر اءة مسمـا يـوفر

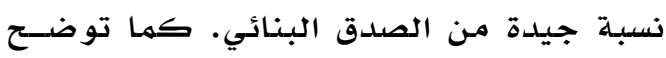
النتائج أن مفردات اختبار PIRLS2011 تتمتع بخصائص سيكو مترية جيدة، في ضوء نموذج

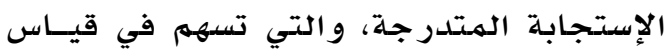
السمـة لدى الطلبة بدقة. حيث نجد أن جميع

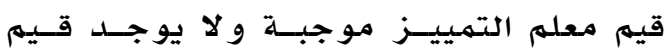
سالبـة وذلك يدل على حرص معدي الإختبار على صياغة المفردات بشكل جيد، حيث أثـار Baker (2001) السـالب تدل على سوء صياغة المفردات و التي

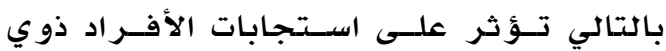
القدرات الهـر تفعـة. كهــا أن قلــة الهـــردات

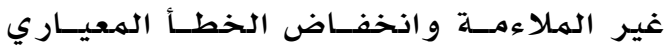
لتقدير ات معالهم المفردات يــدل علـى ثبـات

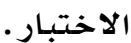
كما تتوزع معلمهة صعوبة أغلـب المفـردات

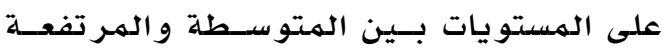

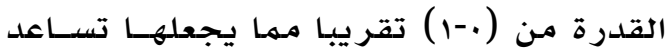
على التمييز بشكل أكبر و تعطـي معلومـــات

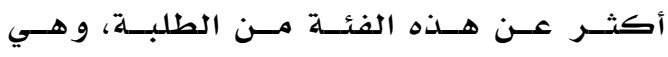
معلومات تتناسب مـع أهــداف اختبــار قيــاس 
الحجازين، نايل عيد (ع.ب). نمـاذج نظريـة الاســتجابة للمفـردة متعــدادة التــدريج

متعددة الأبعاد وبرامجهـا الحاسـوبية. عمان: دار جليس الكتاب.

حمادنة، إياد محمد (q..... ) . استخدام نظرية الاسـتجابة للمفـردة فـي بنــاء اختبـار

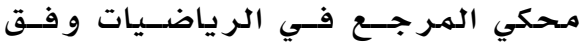
النموذج اللوجستي ثلاثي المعله .مجلة المبلة

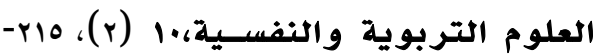
.rMA الرحيل، راتب صـايل (rا.r). أثر وجـود اداء

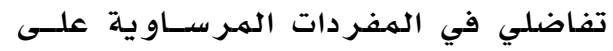

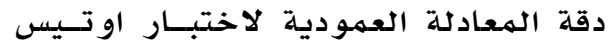

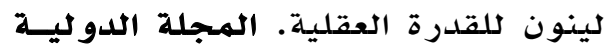

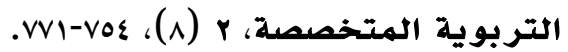

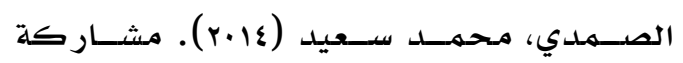
الأطفال المغاربة فـي المبـار اة الدوليسة

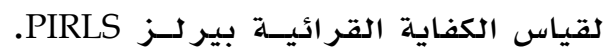

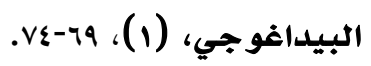

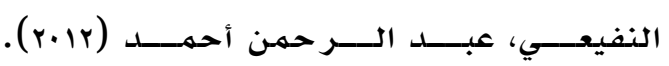

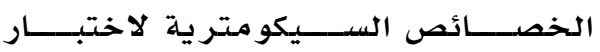

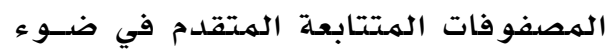
نظرية الاستجابة للمفـردة الاختباريسة.

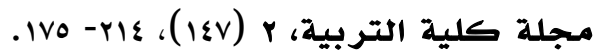

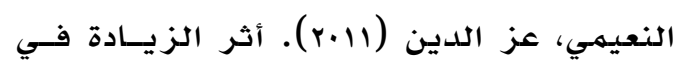

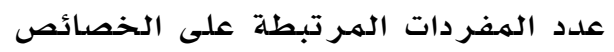

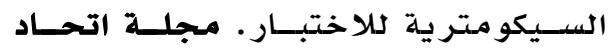
الجامعات العربية للتربية وعلم النفس،

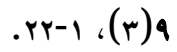

عبد الوهاب، محمد محمود (.1.r). استخدام

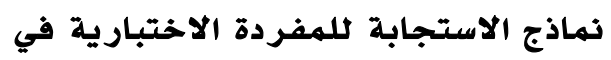
تـــدريج مفـــردات بعـضض الاختبــــارات

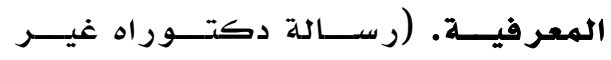

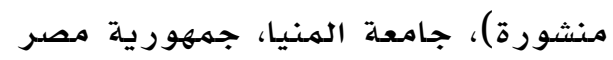

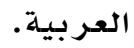

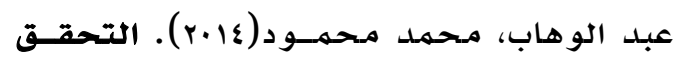
الامبريقي من تكافؤ افتراضـي الحاديــة البعد والاستقلال الموضعي للمفــردات.
ء. تبني استراتيجيات للتعامل مـع الـــص

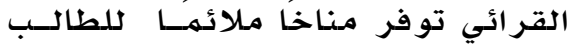

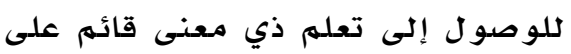

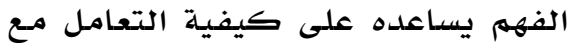

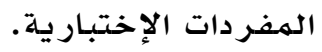

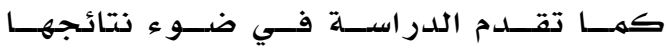
المقترحات البحثية التالية:

إجراء دراسة مقارنة بـين النظريسة

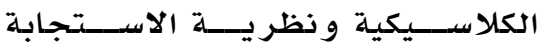

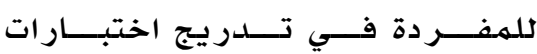
الدر اسة الدو لية PIRLS2011.

إجراء دراسة لمعرفــة أثـر اخستلاف

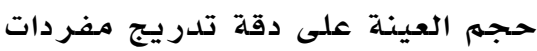

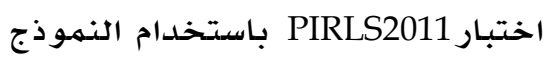
الاستجابة المتدرجة.

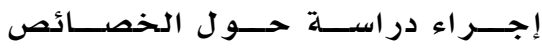
السـيكو مترية لاختبـار PIRLS لعـام

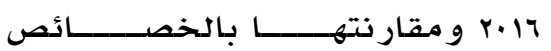
PIRLS2011 السـيكو مترية لاختبـار

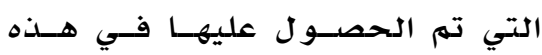
الد الدر اسلة.

\section{المر اجع}

\section{References}

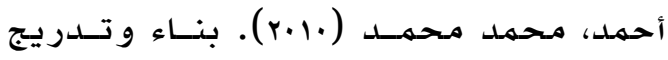
بطاريسـة لقيساس الاستعداد الأكسـاديمي للقبول بالجامعات باستخدام الاختبـارات

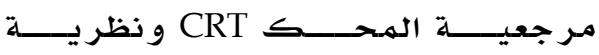

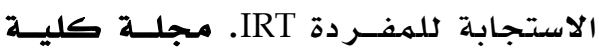

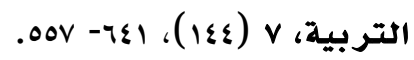

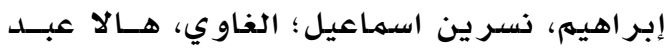

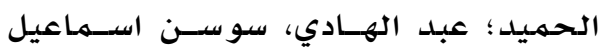

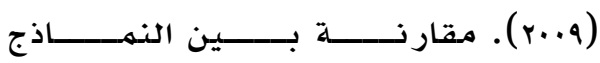
اللوغاريتمية لنظرية الاستجابة للمفردة

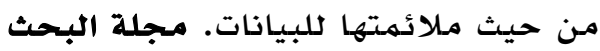

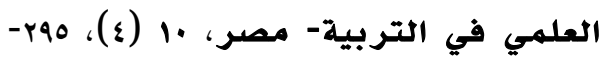
.rYA 
Baker, F. B. (2001). The basics of item response theory. USA: Eric.

Foy, P., Martin, O., Mullis, V. S., \& Stanco, G. (2011). Methods and proceduresreviewing the TIMSS and PIRLS 2011 achievement item statistics. Chestnut Hill: Boston college. Retrieved from http:timssandpirls.bc.edu. 18/12/2016.

Gleason, J .(2008). An evaluation of mathematics competitions using item response theory. Notices of The Ams, 55 (1), 8-15.

IEA's Progress in international reading literacy study. (2011). Methods and procedures- sampling implementation. Chestnut Hill: Boston college. Retrieved from http:timssandpirls.bc.edu. 18/12/2016.

IEA's Progress in international reading literacy study. (2011). Population coverage and sample participation ratesAppendix- C. Chestnut Hill: Boston college.

Kolen, M., J. \& Brennan, R.L. (2004). Test equating, scaling, and linking: methods and practice. New York: Springer.

Marian, S., \& Jay, C. (2001). Developing the PIRLS reading assessment. In Campbell, J. R., Kelly, D. L., Mullis, I.V. S., Martin, M.O., \& Sainsbury, M. (2001). Framework and specifications for PIRLS assessment 2001. (2nd ed.). Chestnut Hill, MA: Boston college.

Mullis, V. S., Martin, O., Kennedy, A. M., Tong, L., Sainsbury, M. (2009). PIRLS 2011 assessment framework. Chestnut Hill: Boston college.

Mullis,V., Martin, O., Minnich, A., Drucker, T., \& Ragan, A. (2012). PIRLS 2011 encyclopedia- education policy and curriculum in reading- volume 1:AK. Chestnut Hill: Boston college.

Mullis,V., Martin, O., Minnich, A., Drucker, T., \& Ragan, A. (2012). PIRLS 2011 encyclopedia- education policy and curriculum in reading- volume 2:LZ. Chestnut Hill: Boston college.

Mullis, V. S., Martin, O., \& Foy, P. (2011). The impact of reading ability on

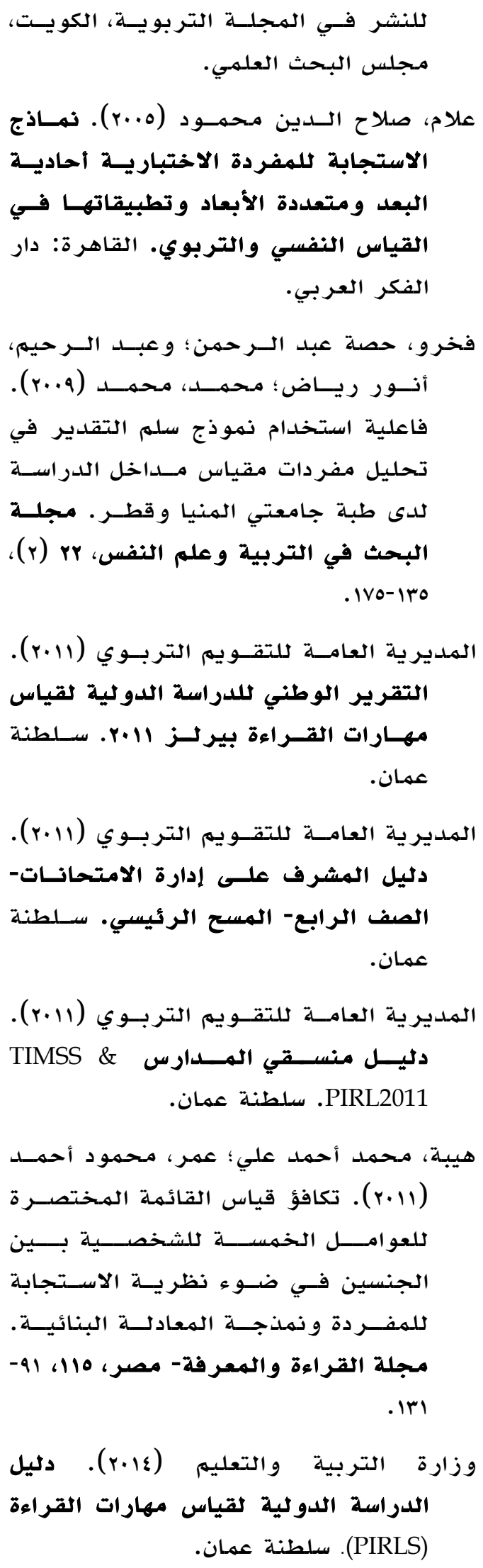


TIMSS mathematics and science achievement at the fourth grade: An analysis by item reading demands. TIMSS and PIRLS 2011, 67-108.

Oishi, S. (2005). The concept of life satisfaction across cultures: An IRT analysis. Journal of Research in Personality, 40(4), 411-423.

Ratri, S. Y. (2015). Student factor infl uencing Indonesian student reading literacy based on PIRLS data 2011. Journal Of Education, 1(1), 24-32.

Reese, L. M. (1999). A classical test theory perspective on LSAT local item dependence. LSAC research report series. Statistical report.

Stage, C. (2003). Classical test theory or item response theory: The swedish experience. Santiago, Chile.

Scherbaum, C. A., Cohen-Charash, Y., \& Kern, M. J. (2006). Measuring general self-efficacy: A comparison of three measures using item response theory. Educational and Psychological Measurement, 66(6), 1047-1063.

Sijetsma, K. Junker, B.(2006). Item response theory: Past performance, present development, and future expectations. Behaviormetrika, 33 (1), 75-102.

Tunmer, W. E., Chapman, J. W., Greaney, K. T., Prochnow, J. E., \& Arrow, A. W. (2013). Why the New Zealand National Literacy Strategy has failed and what can be done about it: Evidence from the Progress in International Reading Literacy Study (PIRLS) 2011 and Reading Recovery monitoring reports. Australian Journal of Learning Difficulties, 18(2), 139-180.

Ueno, M. (2002). An extension of the IRT to a network model. Behaviormetrika, 29(1), 59-79.

Yang, W. L., \& Houang, R. T. (1996). The effects of anchor length and equating method on the accuracy of test equating: Comparisons of linear and IRT-based equating using an anchor-item design. Paper presented at the annual meeting of the American Educational Research Association, New York.

Zenisky, A., Hambleton, R., \& Sireci, S. (2002). Effects of local item dependent on the validity of IRT item, test and ability statistics. Unpublished Phd thesis. University of Massachusetts.

Zimmerman, L. (2014). Lessons learnt: Observation of Grade 4 reading comprehension teaching in South African schools across the Progress in International Reading Literacy Study (PIRLS) 2006 achievement spectrum. Reading \& Writing-Journal of the Reading Association of South Africa, 5(1), 1-9.

Zubairi, A. M., \& Kassim, N. L. A. (2016). Classical and Rasch analyses of dichotomously scored reading comprehension test items. Malaysian Journal of ELT Research, 2(1), 1-26. 
ملحق 1

قائمة الأشكال:
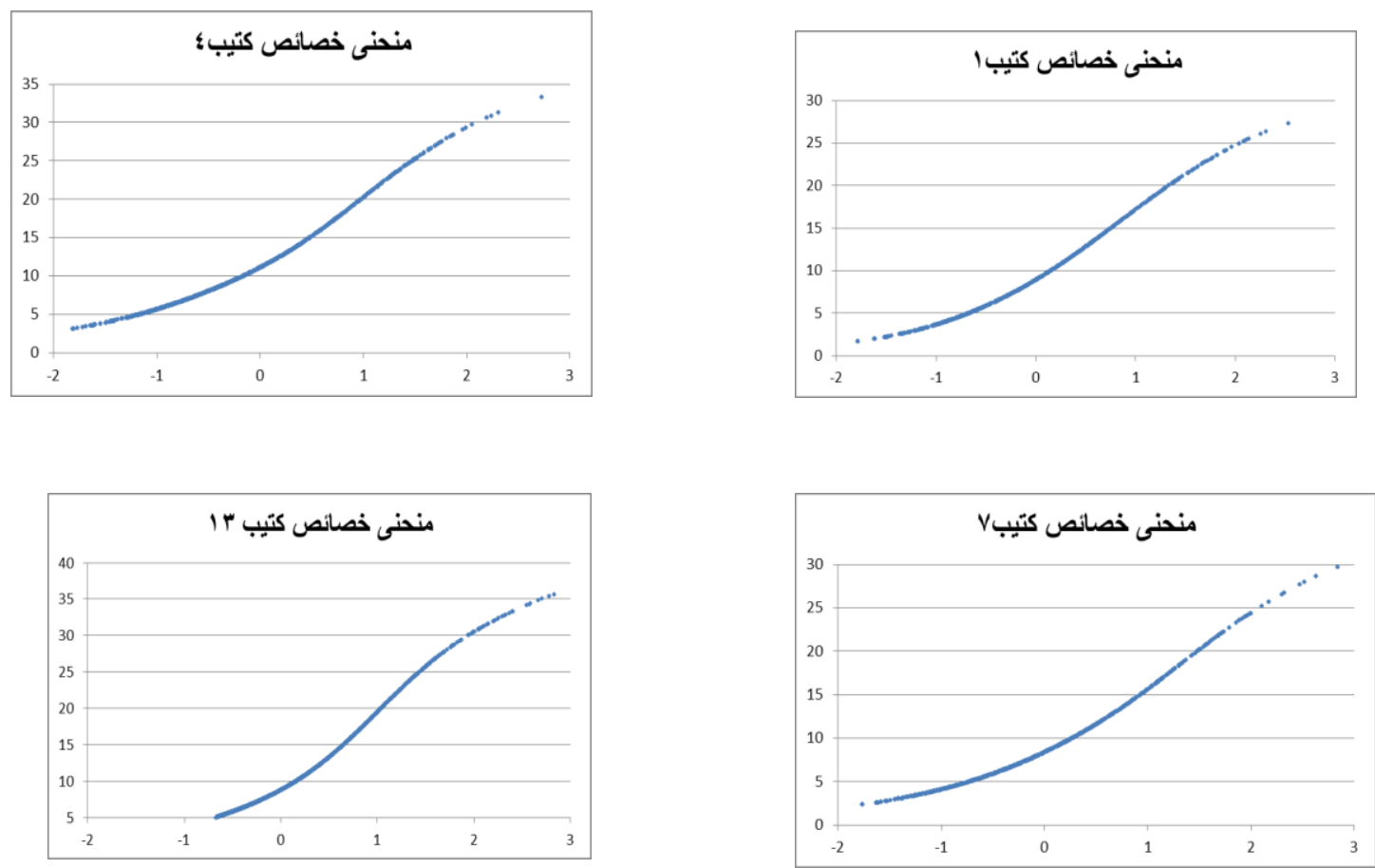

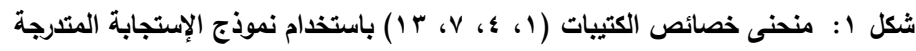

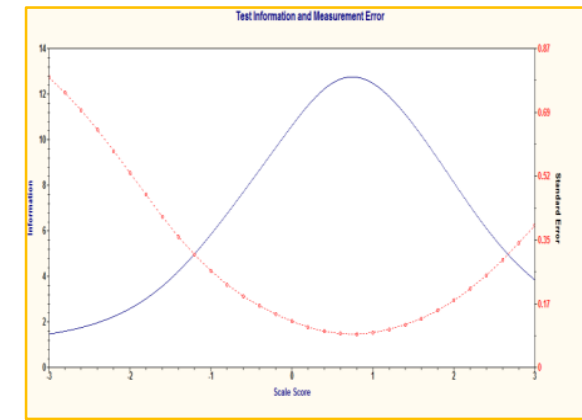

كتيب

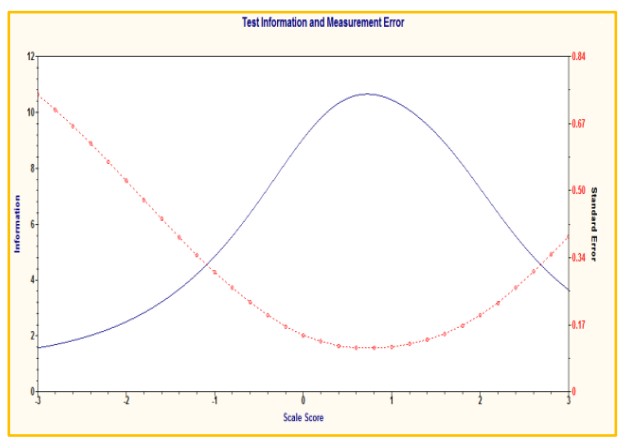

كتيب 9

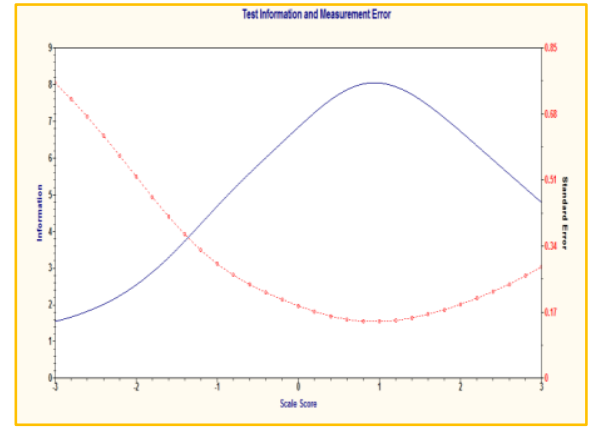

كتيب1

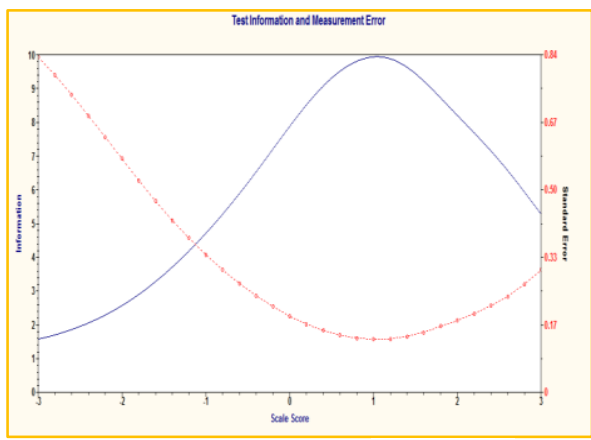

كتيب 7

شكل ץ: منحنيات معلومات الكتيبات (1، 0، 7، 9) 